\title{
Synthesis, optical and electrochemical properties of a series of push-pull dyes based on the 4,4-bis(4-methoxy phenyl)butadienyl donor
}

Corentin Pigot ${ }^{1}$, Guillaume Noirbent ${ }^{1}$, Thanh-Tuân Bui ${ }^{2}$, Sébastien Péralta ${ }^{2}$, Sylvain Duval ${ }^{3}$, Malek Nechab ${ }^{1}$, Didier Gigmes ${ }^{1}$ and Frédéric Dumur ${ }^{1, *}$

1 Aix Marseille Univ, CNRS, ICR UMR7273, F-13397 Marseille France

2 CY Cergy Paris Université, LPPI, F-95000 Cergy, France

${ }^{3}$ Université de Lille, CNRS, Centrale Lille, ENSCL, Univ. Artois, UMR 8181 - UCCS Unité de Catalyse et Chimie du Solide, F-59000 Lille, France

* Correspondence: frederic.dumur@univ-amu.fr

\begin{abstract}
A series of twelve dyes based on the 4,4-bis(4-methoxyphenyl)butadienyl donor and differing by the electron acceptors have been designed and synthesized. The different dyes were characterized by UV-visible absorption spectroscopy as well as cyclic voltammetry. By fine tuning the electron-accepting ability of the fourteen selected acceptors, dyes absorbing between 400 and $650 \mathrm{~nm}$ could be obtained with this $\pi$-extended donor. To get a deeper insight into the optical properties, solvatochromism was investigated in 23 different solvents and remarkable linear correlations could be obtained using the Taft and Catalan solvatochromism scales. A comparison with four dyes used as reference compounds and differing from the series of twelve dyes by the structure of the electron-donating groups was also established so that the electron releasing ability of the 4,4-bis(4-methoxyphenyl)butadienyl donor could be compared with the reference ones. To prepare these four references compounds, only two electron acceptors previously used for the design of the twelve dyes have been employed. Interestingly, variation of the absorption maxima of the twelve dyes was determined as being more influenced by the polarizability of the solvent rather than by its polarity. To support the experimental results, theoretical calculations were carried out.
\end{abstract}

\section{Keywords:}

Push-pull dyes, Michler's aldehyde, solvatochromism, TNF, TCF, rhodanine, indanedione 


\section{Introduction}

During the past decades, organic dyes have been the subject of numerous research efforts due to the wide range of applications in which these dyes are involved, ranging from emitters for organic light-emitting diodes,[1-3] chromophores for organic solar cells,[4-6] dyes for Non-Linear Optical applications,[7-9] fluorescent probes for various biological applications,[10-11] photoinitiators of polymerization,[12-21] sunlight induced polymerization [22-26] or photoredox catalysis.[27-30] When dyes of high molar extinction coefficients are researched, an effective strategy to get this intense absorption consists in developing molecules in which the electron donor is separated from the electron acceptor by mean of a conjugated spacer.[31-32] As a result of the presence of both an electron donating and an electron-accepting group, a strong electronic delocalization within the $\pi$-conjugated system can occur, giving rise in the visible range to an intense absorption band corresponding to the intramolecular charge transfer (ICT) band. To enhance the molar extinction coefficient, the oscillation strength should be increased, what can be obtained by increasing the number of electrons involved in the electronic delocalization. In this aim, elongation of the $\pi$-conjugated spacer is an effective strategy which was applied to the design of numerous dyes.[33-35] Parallel to this, the $\pi$ conjugated spacer being included into the Highest Occupied Molecular Orbitals (HOMO), a destabilization of the HOMO level is jointly observed, reducing the HOMO-LUMO gap (where LUMO stands for Lowest Unoccupied Molecular Orbital) and red-shifting the absorption. Among electron donors, the 4,4-bis(aryl)butadienyl donors have been identified as promising candidates for the design of dyes exhibiting a pronounced solvatochromism.[36-37] Besides, the number of push-pull dyes designed with these electron-releasing groups remain scarce, as exemplified by the dyes PP1-PP35 reported in the Figure 1.[38-42] If most of these structures have been examined for their solvatochromic properties, it has to be noticed that PP6, PP28, PP29, PP31, PP33, PP34 and PP35 have been tested as photoinitiators of polymerization due to their strong absorption extending over the visible range.[41] Conversely, PP30 and PP32 have been specifically designed as proligands to complex metal cations[40] whereas PP19 and PP20 have only been reported as structures. To date, the 4,4-bis(4-methoxyphenyl)butadienyl donor has only been scarcely used for the design of push-pull dyes since only three dyes i.e. PP5, PP11 and PP17 are reported to date. Besides, numerous electron acceptors are reported in the literature[43] so that this electron donor deserves to be studied with a wider range of electron acceptors. As earlier mentioned, push-pull dyes are now extensively studied as photoinitiators of polymerization activable in the visible range and under low light intensity. 
Fine tuning of the absorption properties over the visible range is therefore an urgent need of photopolymerists. Indeed, an optimal monomer conversion can be achieved while adjusting the absorption maxima of dyes with the emission wavelengths of the light sources. Therefore, all electron donors, even if weak electron donors, can be of interest to design dyes whose absorption maxima could coincide with the emissions of the irradiation sources. Parallel to this, the substitution pattern of dyes can drastically impact the solubility of dyes in resins. Therefore, investigations of new groups that can improve the solubility of dyes in resins is also a key parameter governing the polymerization efficiency.

In this work, a series of twelve dyes PP5, PP6, PP11, PP15 and D1-D9 differing by the electron acceptors have been designed and synthesized (See Figure 2). The different dyes have been characterized by different techniques including UV-visible absorption spectroscopy and cyclic voltammetry. Parallel to this, the solvatochromic properties of the different dyes have been examined while using different solvatochromic scales. 


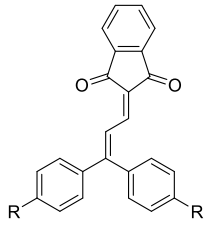

$P P 1: R=H$

PP2: R $=F$

PP3 : $\mathrm{R}=\mathrm{Cl}$,
PP4: $\mathrm{R}=\mathrm{Me}$

PP5: $\mathrm{R}=\mathrm{OMe}$

PP6: $R=\mathrm{NMe}_{2}$

[33],[38]

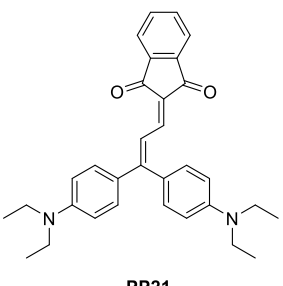

[35]

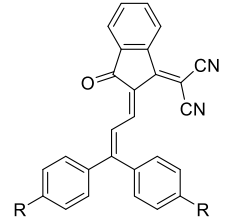

PP7 : R = H

PP9 : $R=\mathrm{Cl}$
PPIO

PP10: $R=M e$

PP11: $R=O M e$

PP12: $\mathrm{R}=\mathrm{NMe}_{2}$

[34]

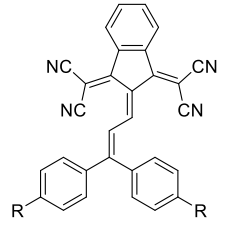

PP13: $\mathrm{R}=\mathrm{H}$

PP14: R = F

$P P 15: R=C l$,
$P P 16: R=M e$

$P P 17: R=O M e$

PP18: $R=\mathrm{NMe}_{2}$

[34]

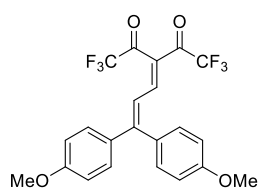

PP19

[36]

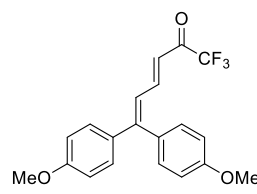

PP20

[36]

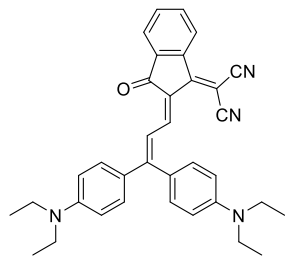

PP22

[35]

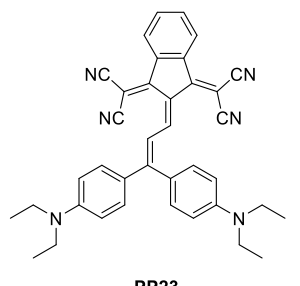

PP23

[35]

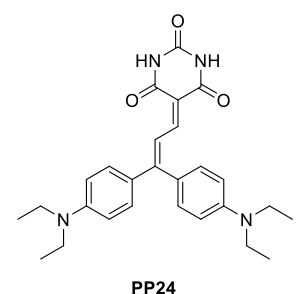

[35]

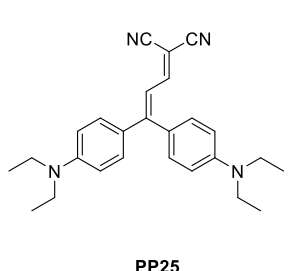

[35]

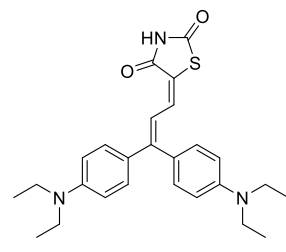

PP26

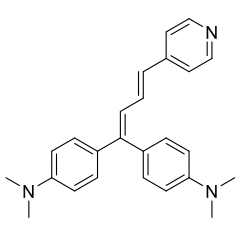

PP27

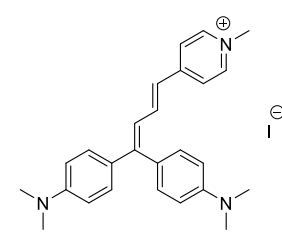

PP28

[37]

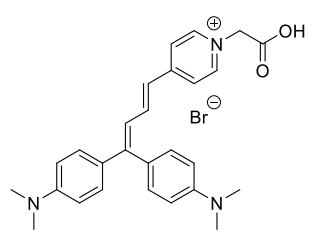

PP29

[39]

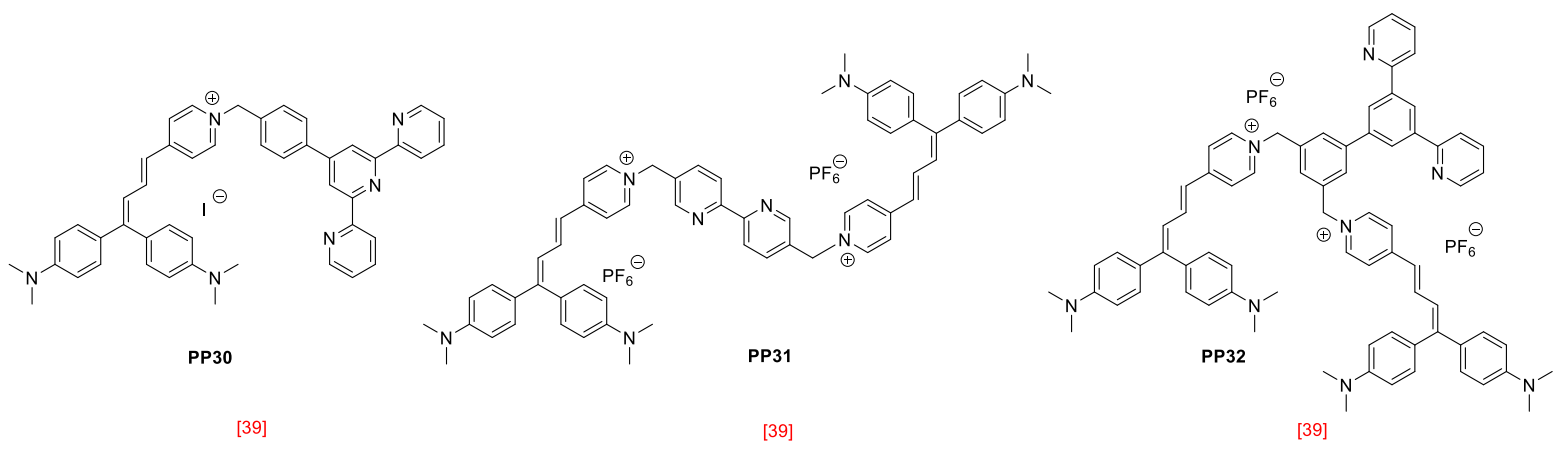

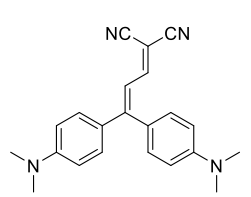

PP33

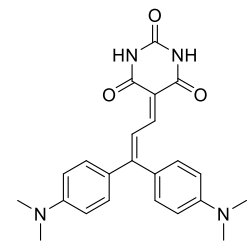

PP34

[38]

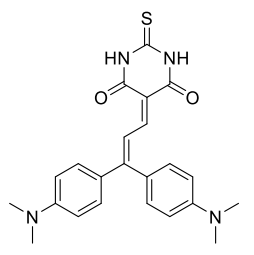

PP35

Figure 1. Chemical structures of dyes PP1-PP35 reported in the literature.

To evidence the real electron-donating ability of the 4,4-bis(4-methoxyphenyl)butadienyl donor, comparisons with four dyes PP6, D10-D12 differing from PP5, PP11, PP17 and D1D9 by the electron donors have also been synthesized. Finally, to support the experimental results, theoretical calculations were carried out. 


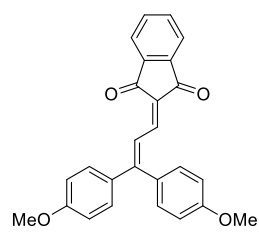

PP5

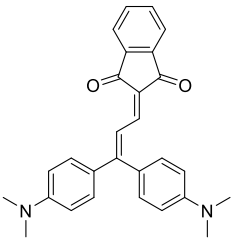

PP6

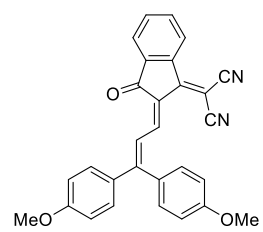

PP11

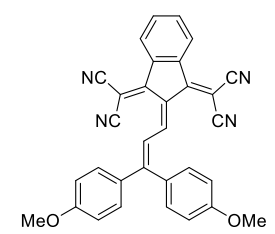

PP17

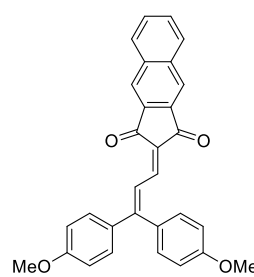

D1

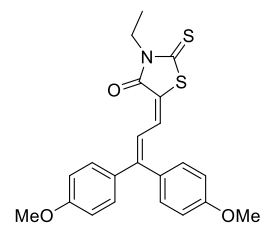

D6

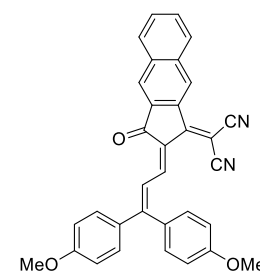

D2

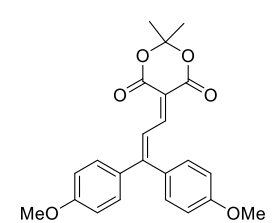

D3

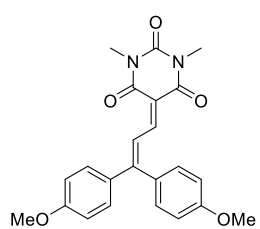

D4

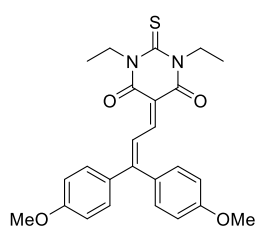

D5

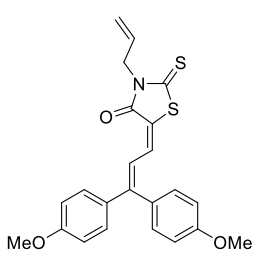

D7

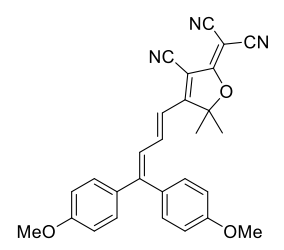

D8

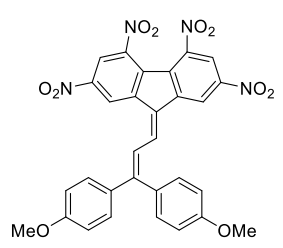

D9

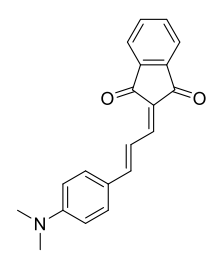

D10

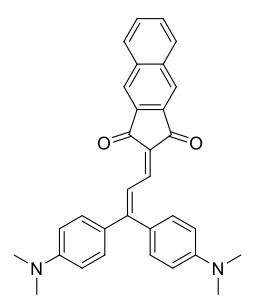

D11

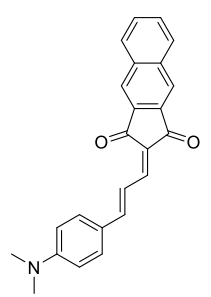

D12

Figure 2. Chemical structures of the sixteen dyes PP5, PP6, PP11, PP17 and D1-D12 investigated in this work.

\section{Results and Discussion}

\subsection{Synthesis of the dyes}

The sixteen dyes PP5, PP11 and D1-D11 reported in this work have been synthesized using a standard method consisting in a Knoevenagel reaction. Even if this reaction was reported as soon as 1896 by Knoevenagel between benzaldehyde and ethyl acetoacetate in the presence of piperidine as the catalyst,[44] this latter was not adapted for the synthesis of dyes PP11 and D2 for which diisopropylethylamine (DIPEA) was used instead of piperidine. Indeed, as evidenced by recent reports in the literature, in the case of dyes based on 2-(3-oxo-2,3dihydro-1 $H$-inden-1-ylidene)malononitrile $\quad$ EA2, 2,2'-(1H-indene-1,3(2H)-diylidene) dimalononitrile EA3 or extended analogues such as EA5, an unexpected cyclization reaction 
can occur, resulting from the nucleophilic attack of the secondary amines onto the cyano groups, producing azafluorenones.[45-49] By opposing 3,3-bis(4-methoxyphenyl)acrylaldehyde ED1, Michler's aldehyde (3,3-bis(4-(dimethylamino)phenyl)acrylaldehyde) ED2 or 3-(4(dimethylamino) phenyl)acrylaldehyde ED3 to the appropriate electron acceptors EA1-EA12 in the presence of piperidine or DIPEA, the different dyes could be isolated in pure form with reaction yields ranging from $75 \%$ for $\mathbf{D 3}$ to $92 \%$ for PP11 respectively (See Scheme 1).
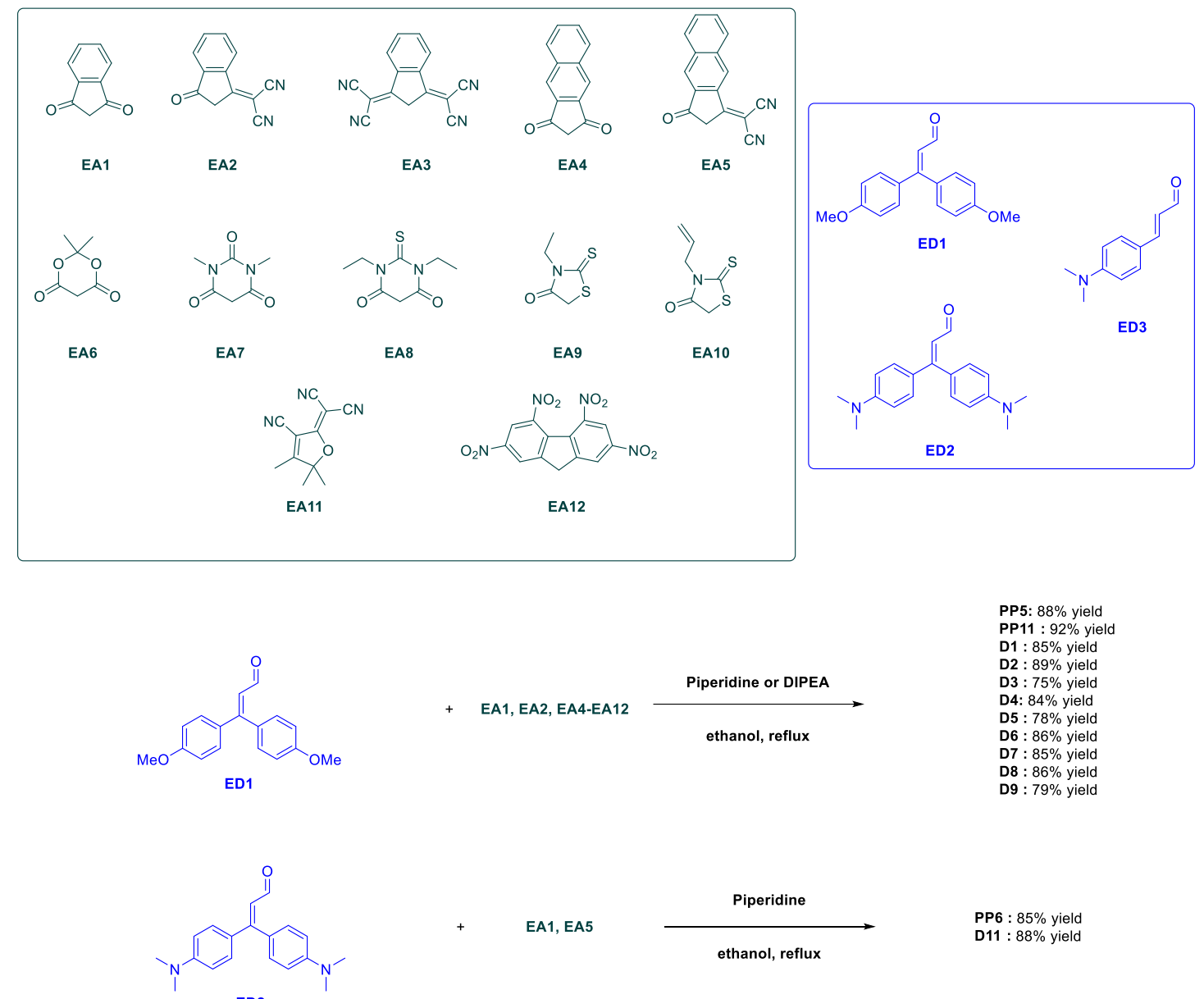

ED2

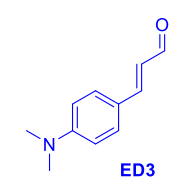

EA1, EA5

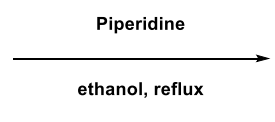

D10 : $89 \%$ yield D12 : $84 \%$ yield

Scheme 1. Synthetic routes to the sixteen dyes PP5, PP11 and D1-D11 reported in this work.

Finally, due to the remarkable stability of the EA3 anion in basic conditions, condensation of EA3 on ED1 could not be carried in these conditions and the Knoevenagel reaction could only been carried out in acidic conditions, in this case acetic anhydride. At the end, PP17 could be isolated in pure form in $94 \%$ yield. 

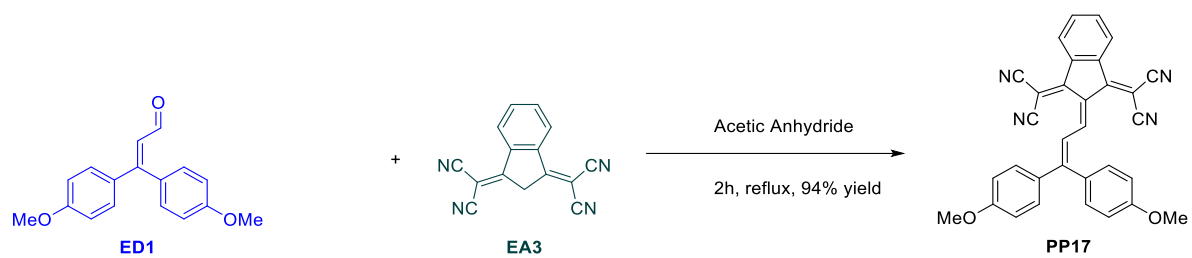

Scheme 2. Synthetic route to PP17.

It has to be noticed that among the twelve electron acceptors used in this study, EA2, [50] EA3,[51] 1H-cyclopenta[b]naphthalene-1,3(2H)-dione EA4,[52] 2-(3-oxo-2,3-dihydro-1Hcyclopenta[b] naphthalen-1-ylidene)malononitrile EA5,[45,53] 2-(3-cyano-4,5,5trimethylfuran-2(5H)-ylidene) malononitrile EA11[54] and 2,4,5,7-tetranitro-9H-fluorene EA12[55-56] have been prepared according to procedures previously reported in the literature. The different dyes (except PP17) were also synthesized in ethanol which is a biosourced solvent so that the concepts of Green Chemistry have been applied to their syntheses. All dyes could be obtained in pure form by simple filtration on a glass filter, which is the simplest procedure to purify compounds. Among the series of 16 dyes examined in this work, only 7 of them (PP5, PP11, PP17, D1, D2, D10-D12) have previously been reported in the literature, demonstrating the novelty and the systematic approach developed in this work.

Finally, by slow evaporation of chloroform, crystals could be obtained for several dyes, and their structures could be solved by single-crystal X-ray diffraction as exemplified with PP5 and PP17 (See Figure 3). It has to be noticed that in the crystal structure of PP17, a cocrystallization with chloroform molecules could be clearly evidenced. As shown in the Figure 3, a fully planar structure could be found between the electron donor and the electron-accepting moiety, optimizing the electronic delocalization between the two partners. However, a torsion angle can be found between one of the aromatic rings of the electron-donating group and the rest of the structure. Thus, an angle of $73.3^{\circ}$ could be determined for PP5 whereas this angle increased up to $75.1^{\circ}$ in PP17. The higher deviation found in PP17 can be assigned to the steric hindrance generated by the dicyanovinylene group, enforcing a rotation of one of the aromatic rings. Conversely, in the case of PP5, a reduced steric hindrance exists between the oxygen atom of the acceptor and the methoxyphenyl group so that a reduced dihedral angle could be determined. Interestingly, a drastic influence on the planarity of the structure could be found. Thus, if the electron donor is almost coplanar with the electron donor in PP5 (dihedral angle between the donor and the acceptor being of $178.975(55)^{\circ}$, conversely, for PP17, an angle of $147.918(104)^{\circ}$ could be found between the two partners. Even if the lack of planarity of this structure should influence the optical properties and the electronic delocalization of the 
structure, the latter detailed optical properties will reveal that the lack of planarity could not dramatically impact the optical properties, the position of the intramolecular charge transfer (ICT) band of this dye being correctly positioned, with regards to the electron withdrawing ability of EA3 and that of the other electron acceptors.
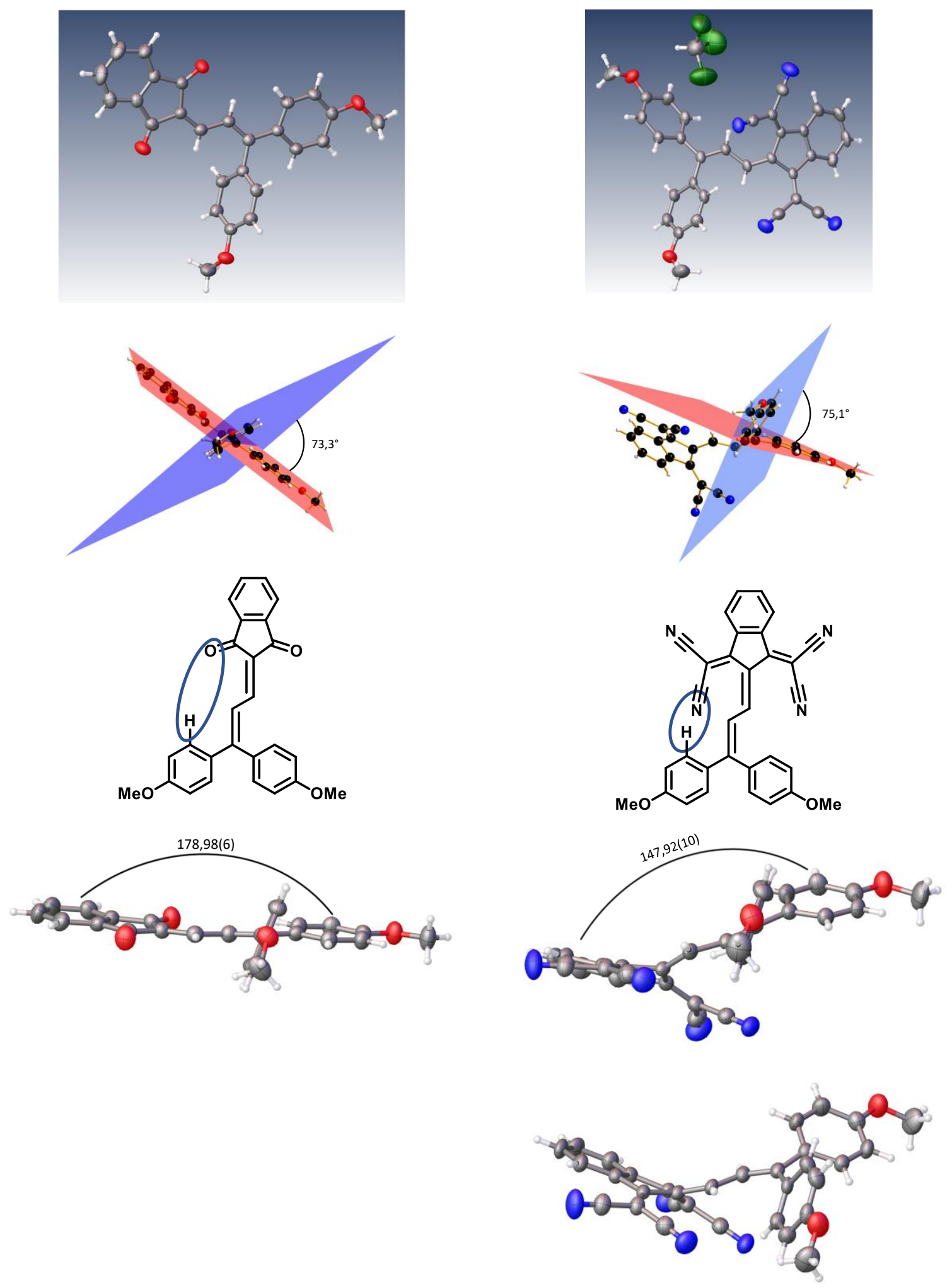

Figure 3. Crystal structures of PP5 (CCDC 2065156) and PP17 (CCDC 2065157). 


\subsection{Theoretical calculations}

The B3LYP/6-311G(d,p) level of theory using Gaussian 09 program have been used for geometry optimization and also for the calculation of the Highest Occupied Molecular Orbital (HOMO) and the Lowest Unoccupied Molecular Orbitals (LUMO) energy levels in chloroform.[57-63] As anticipated, use of a similar electron donor (ED1) in all dyes furnished HOMO orbitals of similar energy levels and with a similar electronic distribution (See Table 1 and Figure 4). On the opposite, a greater modification of the LUMO energy levels could be found, consistent with a modification of the electron-withdrawing abilities of EA1-EA12. By examining the contour plots of the HOMO and LUMO orbitals for PP5, PP11, PP17, D1-D9, a HOMO orbital located on the 4,4-bis(4-methoxyphenyl)butadienyl moiety and a LUMO orbital centered onto the electron acceptor confirmed that the HOMO-LUMO gaps in PP5, PP11, PP17, D1-D9 only varied by the position of the LUMO level.
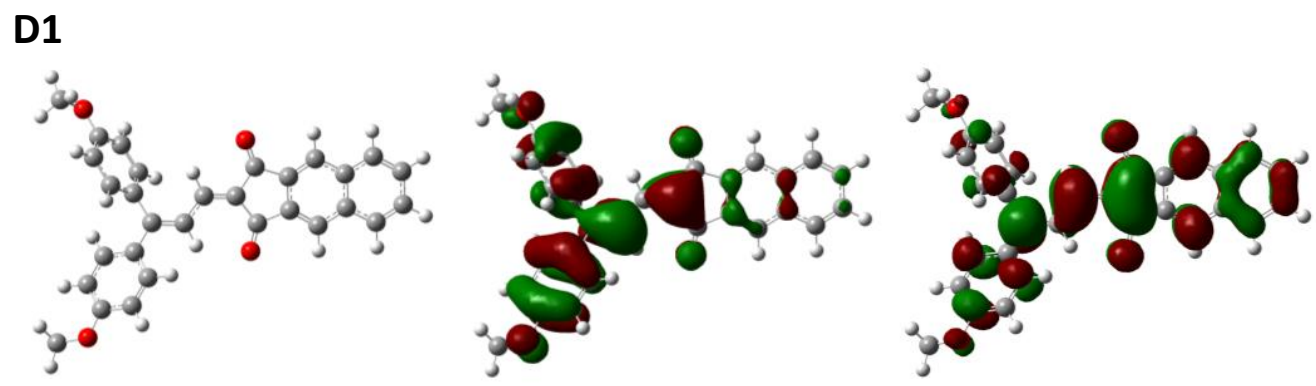

Homo

Lumo
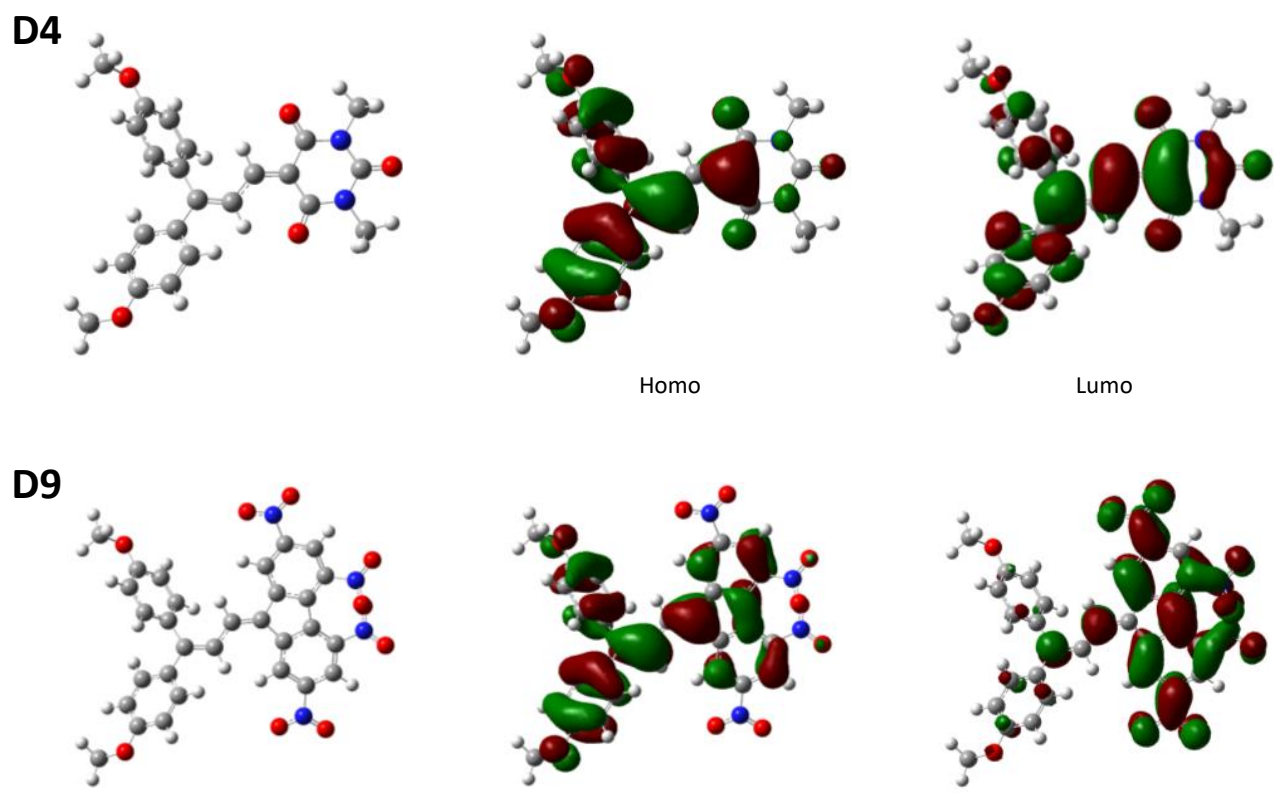

Homo

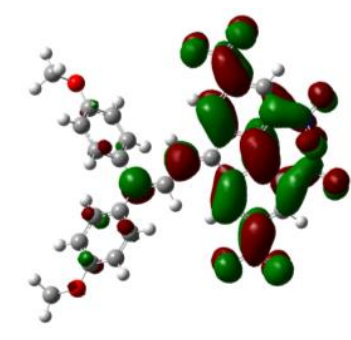

Lumo

Figure 4. Optimized geometries and HOMO/LUMO electronic distributions of D1, D4 and D9. 
Also, to get a deeper insight into the transitions involved in the visible range, DFT calculations were performed using the same model. Chloroform was selected as the solvent and the polarizable continuum model (PCM) was selected as the solvent model for the TD-DFT calculations. A dielectric constant of 4.9 was used for the calculations. The theoretical UVvisible absorption spectra are presented in the Figure 5. A comparison between the theoretical and the experimental UV-visible absorption spectra is provided in the next paragraph.

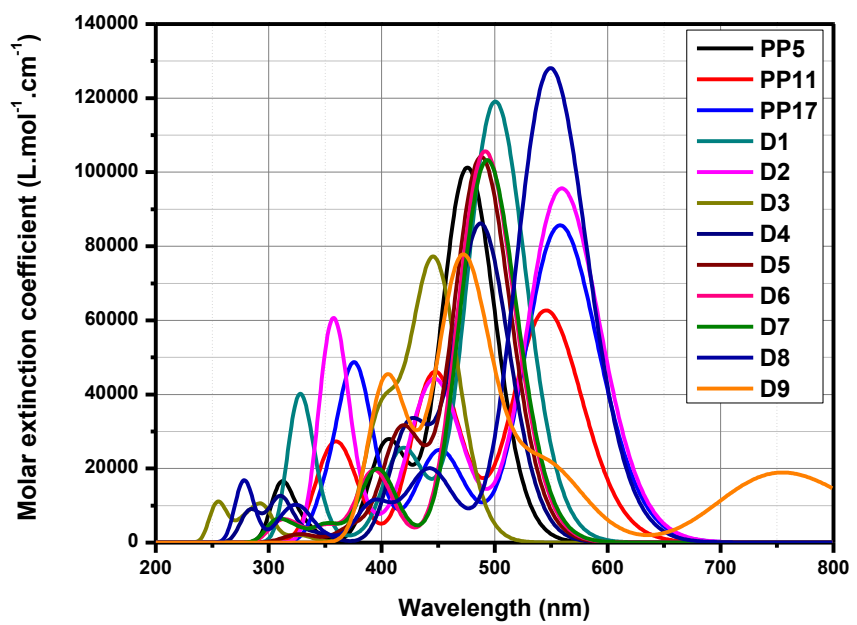

Figure 5. Simulated absorption spectra in dilute chloroform of synthetized compounds PP5, PP11, PP17, D1-D9.

Table 1. Summary of the simulated absorption characteristics in dilute chloroform of the different compounds. Data were obtained in chloroform solutions.

\begin{tabular}{|c|c|c|c|c|}
\hline Compounds & Eномо $(\mathrm{eV})$ & E Lumo $_{\text {LeV })}$ & $\lambda_{\max }(\mathrm{nm})$ & Transitions \\
\hline \multirow[t]{4}{*}{ D1 } & -5.97 & -3.12 & 498 & HOMO->LUMO (99\%) \\
\hline & & & 436 & HOMO-3->LUMO (88\%) \\
\hline & & & 422 & HOMO-1->LUMO (97\%) \\
\hline & & & 414 & HOMO-2->LUMO (90\%) \\
\hline \multirow[t]{5}{*}{ D2 } & -6.01 & -3.44 & 558 & HOMO->LUMO (99\%) \\
\hline & & & 464 & HOMO-1->LUMO (88\%) \\
\hline & & & 451 & HOMO-2->LUMO (98\%) \\
\hline & & & 433 & HOMO->LUMO+1 (83\%) \\
\hline & & & 407 & HOMO-4->LUMO (85\%) \\
\hline D3 & -6.11 & -2.97 & 445 & HOMO->LUMO (97\%) \\
\hline D4 & -6.05 & -2.99 & 457 & HOMO->LUMO (98\%) \\
\hline \multirow[t]{2}{*}{ D5 } & -6.06 & -3.15 & 512 & HOMO-1->LUMO (93\%) \\
\hline & & & 486 & HOMO->LUMO (94\%) \\
\hline
\end{tabular}




\begin{tabular}{|c|c|c|c|c|}
\hline & & & 414 & HOMO-2-> LUMO (98\%) \\
\hline D6 & -5.72 & -2.89 & $\begin{array}{l}490 \\
435\end{array}$ & $\begin{array}{c}\text { HOMO->LUMO (99\%) } \\
\text { HOMO-1->LUMO (90\%) }\end{array}$ \\
\hline D7 & -5.74 & -2.91 & $\begin{array}{l}492 \\
438\end{array}$ & $\begin{array}{c}\text { HOMO->LUMO (99\%) } \\
\text { HOMO-1->LUMO (87\%) }\end{array}$ \\
\hline D8 & -6.02 & -3.45 & $\begin{array}{l}546 \\
437\end{array}$ & $\begin{array}{c}\text { HOMO->LUMO (99\%) } \\
\text { HOMO-1->LUMO (99\%) }\end{array}$ \\
\hline D9 & -6.05 & -3.94 & $\begin{array}{l}733 \\
536 \\
508 \\
490 \\
467 \\
449 \\
415 \\
411\end{array}$ & $\begin{array}{c}\text { HOMO->LUMO }(99 \%) \\
\text { HOMO->LUMO+1 }(97 \%) \\
\text { HOMO-1->LUMO }(94 \%) \\
\text { HOMO->LUMO+2 }(93 \%) \\
\text { HOMO->LUMO+3 }(97 \%) \\
\text { HOMO->LUMO+4 }(97 \%) \\
\text { HOMO-2->LUMO }(94 \%) \\
\text { HOMO-1->LUMO+1 }(87 \%)\end{array}$ \\
\hline D10 & -5.55 & -2.94 & $\begin{array}{l}533 \\
442 \\
411\end{array}$ & $\begin{array}{c}\text { HOMO->LUMO }(100 \%) \\
\text { HOMO->LUMO+1 }(98 \%) \\
\text { HOMO-2->LUMO }(52 \%), \text { HOMO-1->LUMO }(43 \%)\end{array}$ \\
\hline D11 & -5.41 & -2.90 & $\begin{array}{l}569 \\
527 \\
424 \\
422 \\
402\end{array}$ & $\begin{array}{c}\text { HOMO->LUMO }(93 \%) \\
\text { HOMO-1->LUMO }(92 \%) \\
\text { HOMO-4->LUMO }(39 \%), \text { HOMO-3->LUMO }(56 \%) \\
\text { HOMO->LUMO+1 }(86 \%) \\
\text { HOMO-2->LUMO }(88 \%)\end{array}$ \\
\hline D12 & -5.57 & -3.07 & $\begin{array}{l}561 \\
432 \\
422 \\
409\end{array}$ & $\begin{array}{c}\text { HOMO->LUMO (100\%) } \\
\text { HOMO-2->LUMO (79\%) } \\
\text { HOMO-1->LUMO (56\%), HOMO->LUMO+1 }(42 \%) \\
\text { HOMO-1->LUMO (43\%), HOMO->LUMO+1 }(56 \%)\end{array}$ \\
\hline PP5 & -5.97 & -3.00 & $\begin{array}{l}474 \\
415 \\
402\end{array}$ & $\begin{array}{c}\text { HOMO->LUMO (98\%) } \\
\text { HOMO-2->LUMO (81\%), HOMO-1->LUMO (14\%) } \\
\text { HOMO-1->LUMO (65\%), HOMO->LUMO+1 }(21 \%)\end{array}$ \\
\hline PP6 & -5.39 & -2.76 & $\begin{array}{l}541 \\
507 \\
448 \\
404\end{array}$ & $\begin{array}{l}\text { HOMO-1->LUMO (11\%), HOMO->LUMO (89\%) } \\
\text { HOMO-1->LUMO (88\%), HOMO->LUMO }(11 \%) \\
\text { HOMO->LUMO+1 (98\%) } \\
\text { HOMO-3->LUMO (69\%), HOMO-2->LUMO }(25 \%)\end{array}$ \\
\hline PP11 & -6.04 & -3.35 & $\begin{array}{l}543 \\
451 \\
436\end{array}$ & $\begin{array}{l}\text { HOMO->LUMO }(97 \%) \\
\text { HOMO->LUMO+1 }(91 \%) \\
\text { HOMO-1->LUMO }(96 \%)\end{array}$ \\
\hline PP17 & -6.08 & -3.47 & $\begin{array}{l}569 \\
557 \\
450 \\
431\end{array}$ & $\begin{array}{c}\text { HOMO->LUMO+1 }(96 \%) \\
\text { HOMO->LUMO }(99 \%) \\
\text { HOMO-1->LUMO }(98 \%) \\
\text { HOMO-1->LUMO+1 }(99 \%)\end{array}$ \\
\hline
\end{tabular}




\subsection{Optical properties}

Push-pull dyes, which consists in structure combining an electron donor connected to an electron acceptor by mean of a $\pi$-conjugated spacer, are characterized by an intense absorption band in the visible range corresponding to the intramolecular charge transfer (ICT) band. Considering that PP5, PP11, PP17, D1-D9 are soluble in chloroform, their UV-visible absorption properties were examined in this solvent. As shown in the Figure 6, a strong absorption band can be detected in the visible range for all dyes, with absorption maxima ranging from $439 \mathrm{~nm}$ for $\mathbf{D 3}$ bearing the weakest electron acceptor EA6 to $500 \mathrm{~nm}$ for PP17 and $553 \mathrm{~nm}$ for D2, substituted with the strongest electron acceptors EA3 and EA5 respectively. Two groups of dyes can be distinguished. Thus, a first group of dyes absorbing between 435 and $460 \mathrm{~nm}$ can be identified, comprising PP5, D3, D4, D6 and D7. This first family of dyes comprises weak acceptors such as indane-1,3-dione EA1, Meldrum acid EA6, $\mathrm{N}$ methylbarbituric acid EA7 or rhodanines EA9 and EA10. In the second group, dyes such as PP11, PP17, D2, and D8 can be identified, possessing EA2, EA3, EA5 and EA11 as acceptors. Considering that the 12 dyes have been prepared with the same electron donor, EA3 and EA5 are undoubtedly the most electron-accepting groups of the series. Interestingly, a perfect overlap of the ICT bands of D1 and D5 was also detected in chloroform (See Figure 6a), demonstrating that the electron-withdrawing abilities of EA5 and EA8 are rather similar. The same conclusions can also be done while comparing the ICT bands of PP17 and D2 bearing EA3 and EA5 as acceptors. Considering that EA5 is only substituted with two cyano groups, its conversion as a tetracyano-substituted acceptor (as done for EA3) could produce an exceptional electron acceptor. However, all attempts to get this electron acceptor failed. Finally, the most intriguing acceptor of the series was EA12. By using this electron acceptor, a compound (D9) exhibiting two ICT bands could be obtained, with the two maxima located at 469 and $553 \mathrm{~nm}$. D9 showed a broad absorption band extending from the UV to the visible range, namely from $350 \mathrm{~nm}$ to $700 \mathrm{~nm}$ (See Figure 6b). Based on previous works aiming at examining the specificities of the UV-visible absorption spectra of 2,4,5,7-tetranitrofluorenebased push-pull dyes, the absorption band located at long-wavelength can be assigned to an electron density transfer along the axis of the molecule from the donor to the electronwithdrawing fluorene moiety.[64] This band is considered as being the ICT band of the dye. Conversely, at short wavelength, this band was determined as originating from an electron density transfer from atoms adjacent to the polymethine chain and the nitro groups of the 
fluorene acceptor. This band was determined as corresponding to the polymethine nature of the absorption band.

Finally, to position ED1 with regards to the other electron donors, a comparison was established with dyes based on ED2 and ED3. For this purpose, PP6, D10-D12 were synthesized, enabling a comparison with dyes comprising two different electron acceptors, EA1 and EA4. As shown in the Figures $6 \mathrm{c}$ and 6d, a similar trend was found for the two series PP5, PP6 and D1, D10, D11 and D12 respectively, except that a red-shift was observed of the absorption maxima was found for the second series (D1, D11 and D12), consistent with an improvement of the electronwithdrawing ability in EA4. Compared to D10 and D12, a redshift as high as $200 \mathrm{~nm}$ was found for the absorption maxima of PP5 and D1, evidencing the weak electron donating ability of ED1.

a)

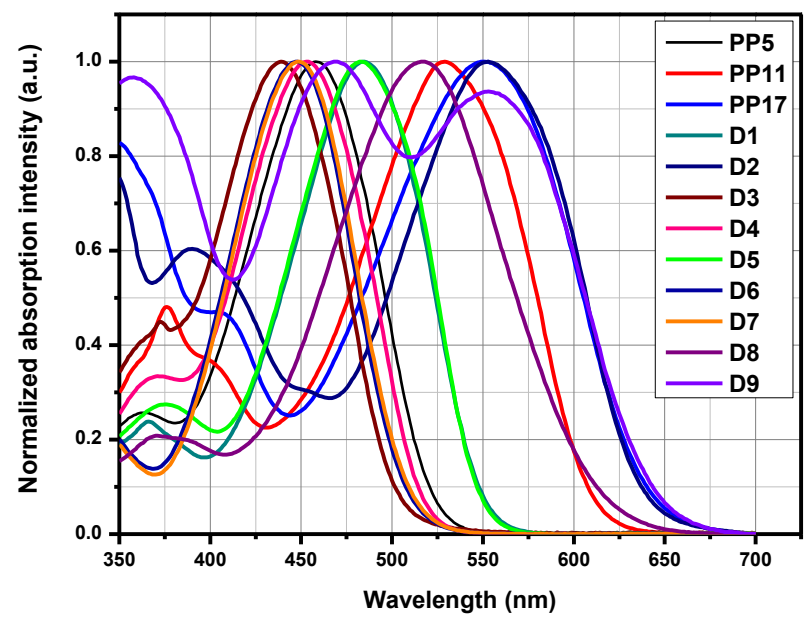

b)

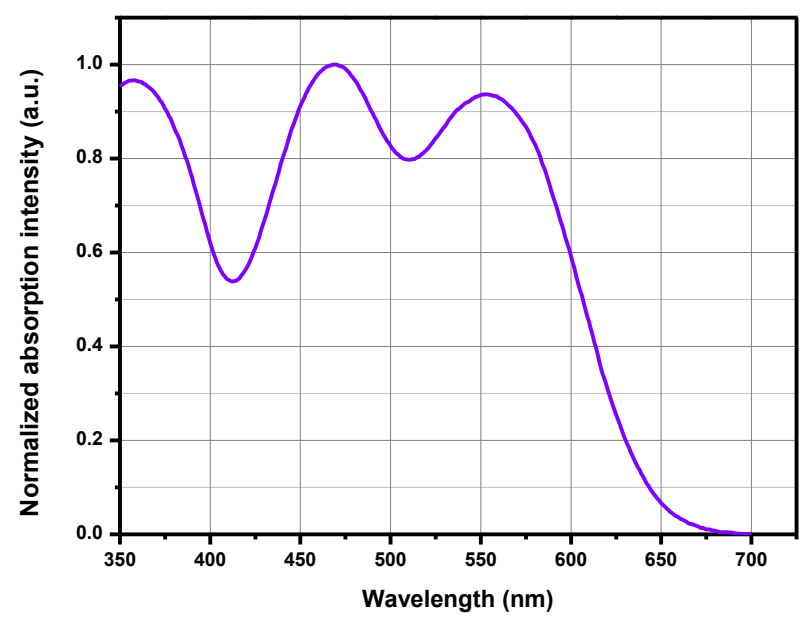


c)

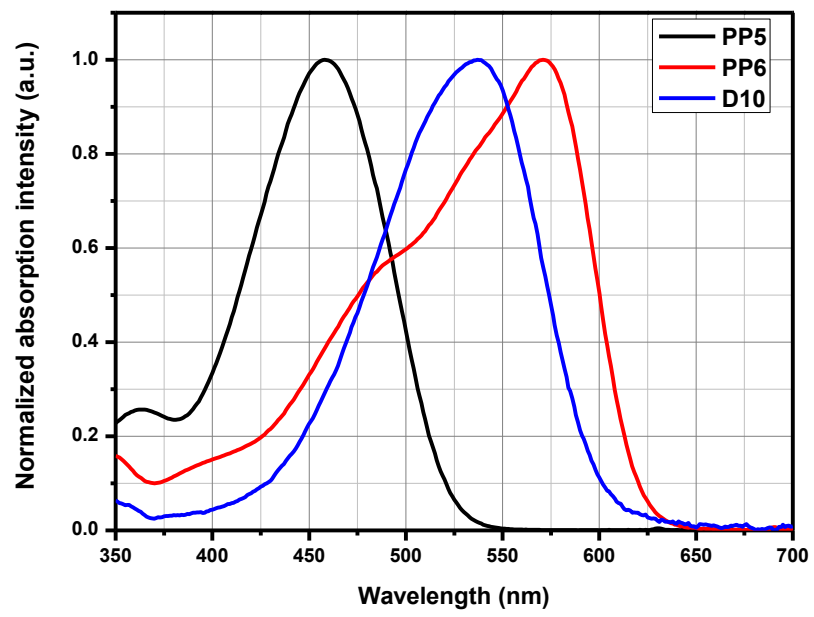

d)

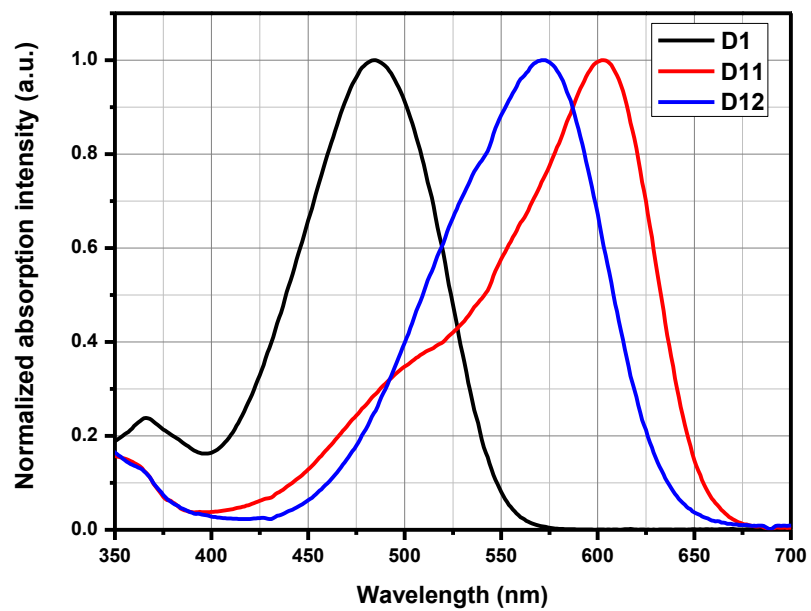

Figure 6. Normalized UV-visible absorption spectra in chloroform of a) PP5, PP11, PP17, D1-D9, b) D9, c) PP5, PP6 and D10, d) D1, D11 and D12.

Examination of their molar extinction coefficients (See Figure 7a and Table 2) revealed PP5, D4 and D7 to exhibit the highest molar extinction coefficients of the series, peaking at 49500,46200 and $52000 \mathrm{M}^{-1} \cdot \mathrm{cm}^{-1}$ respectively. Besides, these values remain far behind that of the reference compounds D11 and D12 for which molar extinction coefficients close to $77000 \mathrm{M}^{-1} \cdot \mathrm{cm}^{-1}$ could be determined (See Figure $7 \mathrm{~b}$ ). The crystal structures have also revealed that the $\pi$-conjugated system of PP5 was fully planar contrarily to that observed in PP17 for which a slightly incurved $\pi$-conjugated system was found. Besides, with regard to the absorption maxima (458 and $550 \mathrm{~nm}$ for PP5 and PP17 respectively), no detectable influence on the electronic delocalization can be detected between these two dyes. Indeed, EA3 is a 
stronger electron acceptor than EA1, supporting the redshift of the ICT band of PP17 by ca. $100 \mathrm{~nm}$ compared to that of PP5.

a)

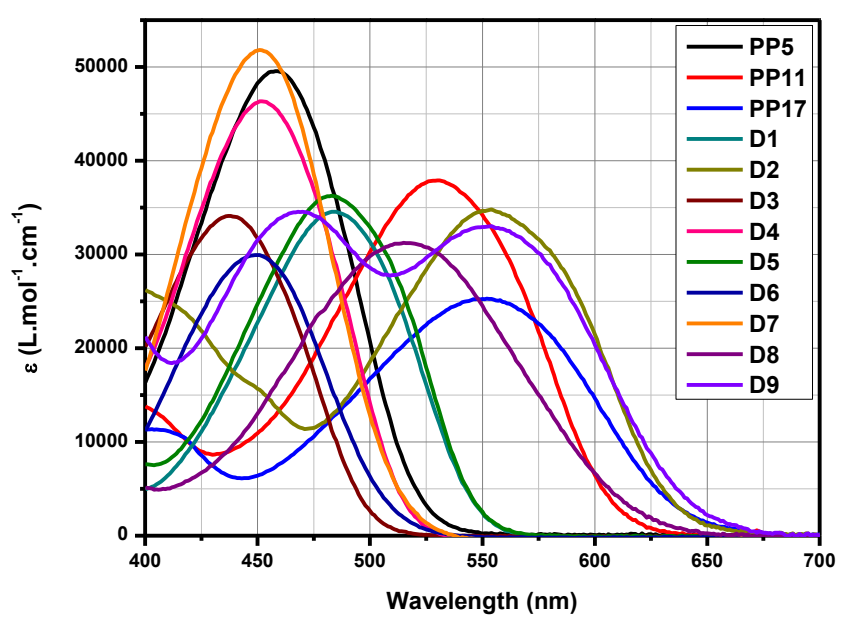

b)

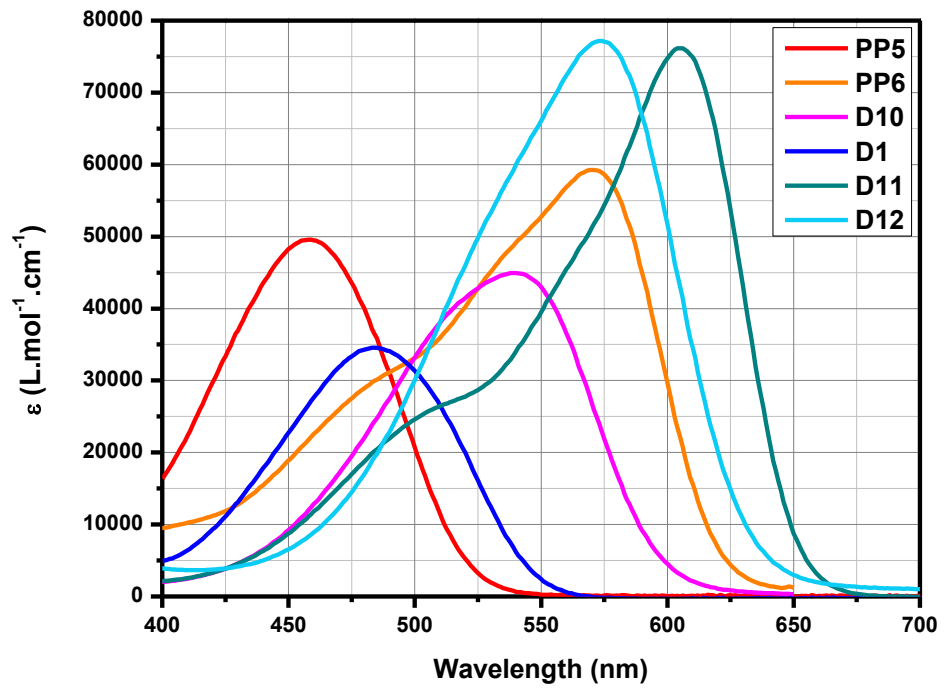

Figure 7. UV-visible absorption spectra in chloroform of a) PP5, PP11, PP17, D1-D9, b) a series of selected dyes PP5, PP6 and D10, d) D1, D11 and D12.

Table 2. Optical characteristics of the different compounds in chloroform and the values theoretically determined.

\begin{tabular}{ccccccccc}
\hline chloroform & & & & & & & & \\
\hline compounds & PP5 & PP6 & PP11 & PP17 & D1 & D2 & D3 & D4 \\
\hline$\lambda(\mathrm{nm})$ & 458 & 571 & 530 & 550 & 484 & 552 & 429 & 452 \\
$\epsilon\left(\mathrm{M}^{-1} \cdot \mathrm{cm}^{-1}\right)$ & 49300 & 59400 & 37800 & 25000 & 34600 & 34800 & 34100 & 46300 \\
$\Delta \mathrm{E}(\mathrm{eV})$ & 2.71 & 2.17 & 2.34 & 2.25 & 2.56 & 2.25 & 2.89 & 2.74 \\
\hline compounds & D5 & D6 & D7 & D8 & D9 & D10 & D11 & D12 \\
\hline$\lambda(\mathrm{nm})$ & 482 & 447 & 449 & 517 & 469,554 & 539 & 606 & 574
\end{tabular}




\begin{tabular}{|c|c|c|c|c|c|c|c|c|}
\hline $\begin{array}{c}\epsilon\left(\mathrm{M}^{-1} \cdot \mathrm{cm}^{-1}\right) \\
\Delta \mathrm{E}(\mathrm{eV})\end{array}$ & $\begin{array}{c}36300 \\
2.57 \\
\end{array}$ & $\begin{array}{c}30000 \\
2.77 \\
\end{array}$ & $\begin{array}{c}51700 \\
2.76 \\
\end{array}$ & $\begin{array}{c}31400 \\
2.40 \\
\end{array}$ & $\begin{array}{c}34500,32600 \\
2.24 \\
\end{array}$ & $\begin{array}{c}44800 \\
2.30 \\
\end{array}$ & $\begin{array}{c}76000 \\
2.04 \\
\end{array}$ & $\begin{array}{c}77100 \\
2.16 \\
\end{array}$ \\
\hline \multicolumn{9}{|c|}{$\begin{array}{l}\text { Theoretical values } \\
\text { in chloroform }\end{array}$} \\
\hline compounds & PP5 & PP6 & PP11 & PP17 & D1 & D2 & D3 & D4 \\
\hline$\lambda(\mathrm{nm})$ & 474 & 528 & 542 & 557 & 499 & 558 & 444 & 458 \\
\hline$\epsilon\left(\mathrm{M}^{-1} \cdot \mathrm{cm}^{-1}\right)$ & 101000 & 116600 & 64300 & 85500 & 118600 & 95100 & 76700 & 86260 \\
\hline$\Delta \mathrm{E}(\mathrm{eV})$ & 2.62 & 2.35 & 2.29 & 2.23 & 2.48 & 2.22 & 2.79 & 2.71 \\
\hline compounds & D5 & D6 & D7 & D8 & D9 & D10 & D11 & D12 \\
\hline$\lambda(\mathrm{nm})$ & 486 & 490 & 491 & 546 & 468,545 & 533 & 542 & 560 \\
\hline$\epsilon\left(\mathrm{M}^{-1} \cdot \mathrm{cm}^{-1}\right)$ & 105000 & 106500 & 103700 & 128800 & 72200,22400 & 97800 & 64300 & 111452 \\
\hline$\Delta \mathrm{E}(\mathrm{eV})$ & 2.55 & 2.53 & 2.52 & 2.27 & 2.27 & 2.33 & 2.29 & 2.21 \\
\hline
\end{tabular}

As experimentally observed, positions of the ICT bands of PP5, PP11, PP17, D1-D9 are clearly redshifted by increasing the electron withdrawing ability of the acceptors. The most redshifted absorptions are detected for PP17, D2 and D9. A good agreement between the theoretical positions of the ICT bands with those of the experimental ones can be detected. Notably, to illustrate this, PP17, D2 and D9, an error lower than $10 \mathrm{~nm}$ can be determined, the experimental ICT bands being located at 550, 552 and $554 \mathrm{~nm}$ vs. 557, 558 and $545 \mathrm{~nm}$ respectively for the theoretical ones. A good agreement between the theoretical and the experimental HOMO-LUMO gaps were also found, the experimental and the theoretical UVvisible spectra being both determined in chloroform. Interestingly, comparisons of the experimental and theoretical values of HOMO-LUMO gaps revealed the theoretical ones to be underestimated, except for PP6 and D11 for which the opposite situation was found. As specificity, the two dyes are based on indane-1,3-dione EA1 and $1 H$-cyclopenta[$[b]$ naphthalene1,3(2H)-dione EA4 as the electron acceptors, that are two acceptors only differing by their polyaromaticities. Only a good agreement between the theoretical and the experimental values was found for D10 and D12 that also bear EA1 and EA4 as the electron acceptors. Clearly, differences between the theoretical and the experimental HOMO-LUMO gaps rely in parameters that are not correctly considered during the calculations such as the internal torsion of the molecules. As shown by the crystallographic structures, one of the two aromatic tings of the electron donating group exhibit a severe deviation relative to the average plane of the molecules due to steric hindrance generated by the electron accepting groups. Contribution of this aromatic ring is not correctly taken into account during the theoretical calculations. Since the same electron donor is used for the design of all dyes (PP5, PP11, PP17, D1-D12), variations of the HOMO-LUMO gap only depends on a modification of the position of the LUMO levels. To evidence this, electronic distribution of the HOMO and LUMO orbitals of PP5, PP11, PP17, D1-D12 was investigated. This part is detailed in the previous section. A 
summary of the main transitions involved in the theoretical UV-visible absorption spectra is provided in the Table 1.

As anticipated for push-pull dyes, the transition detected at the lowest energy mainly arises from a HOMO-> LUMO transition. Parallel to this, in the case of D5, a HOMO-1-> LUMO transition and a HOMO-> LUMO+1 transition for PP17 were determined as the main transitions contributing to the ICT bands. For the transitions at higher energies, an admixture of transitions between HOMO-3, HOMO-2, HOMO-1 -> LUMO, LUMO+1, LUMO+2, LUMO+3 and even LUMO+4 could be determined, depending on the dye. A clear trend can be observed in this series of dyes: When the electron accepting properties of the acceptor part increase, a clear redshift is obtained for the ICT transition.

Within this series of dyes, the values of ELUMO importantly varied as a function of the electron accepting ability of the acceptor part whereas the values of EнOMO slightly changed. These results are in accordance with the fact that the same electron donor has been used in these different dyes and that only the electron acceptors varied. Finally, as mentioned earlier, D9 which possesses TNF as the electron accepting group exhibits two ICT bands detected at 469 and $554 \mathrm{~nm}$ respectively. As shown in the Figure 8, several optical transitions are theoretically predicted in the visible range. Besides, the transition predicted at $740 \mathrm{~nm}$ in chloroform or 770 $\mathrm{nm}$ in acetonitrile was not observed in the experimental UV-visible absorption spectrum. However, two transitions are predicted at higher energy, notably, at 475 and $558 \mathrm{~nm}$ in chloroform, 470 and $560 \mathrm{~nm}$ in acetonitrile, that fit to the two experimental transitions detected at 469 and $554 \mathrm{~nm}$ in chloroform. Based on the theoretical calculations, these two absorption bands are assigned to HOMO-1 -> LUMO and HOMO-> LUMO+1 transitions. 


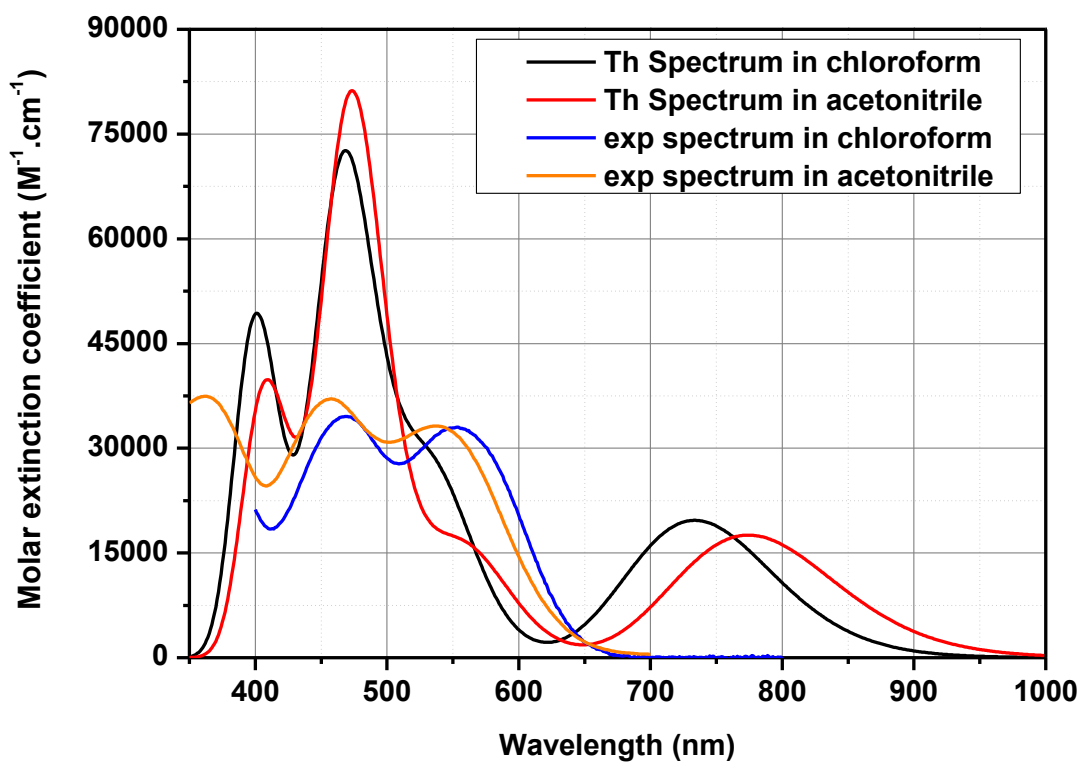

Figure 8. Theoretical and experimental UV-visible absorption spectra of D9 in chloroform and acetonitrile.

\subsection{Solvatochromism}

As evidenced in the previous paragraphs, major differences of the position of the absorption maxima can be found between the different dyes in chloroform, resulting from a modification of the electron accepting groups (EA1-EA12). To get a deeper insight into the absorption properties of PP5, PP11, PP17, D1-D9, their solvatochromic behaviors were examined in 23 solvents of different polarity. A summary of the absorption properties is provided in the Tables 3 and 4. As displayed in these tables, a variation of the positions of the absorption maxima can be clearly evidenced, corresponding to a solvatochromic behaviour. To evidence the intramolecular nature of the charge transfer, dilutions of the solutions were carried out, and a linear decrease of the absorbance vs. the concentration could be obtained for the different dyes. To rationalize the variation of positions of the ICT bands, several solvatochromic scales have been tested, as exemplified by the Kamlet-Taft's,[65] Dimroth-Reichardt's,[66] Lippert-Mataga's,[67] Catalan's,[68-69] Kawski-Chamma-Viallet's,[70] McRae's,[71] Suppan's,[72] Bakhshiev's [73] scales. In these different scales, the polarity and/or the polarizability of the solvents are considered, through parameter such as the solvent polarity parameter $\mathrm{E}_{\mathrm{T}}(30)$ for the Reichardt's scale, the solvent polarizability (SP), the solvent dipolarity (SdP) and the solvent polarity/polarizability (SPP) parameters of the Catalan scales. Parallel to this, Taft parameters $\pi^{*}$ is indicative of the ability of the solvents to stabilize a charge or a dipole by virtue of electric dielectric effects.[64] If the Lippert Mataga scale examines the solvatochromism as a function of the orientation polarizability, the dipole moment and the 
refractive index $n$ of solvents, McRae developed an improved version of the Lippert-Mataga scale by additionally taking into account the solute polarizability for dyes.[67,71] Conversely, the Bakhshiev's, Kawaski-Chamma-Viallet scales examine the variation of excited state dipole moments as a function of the static dielectric constant $\left(\varepsilon_{\mathrm{r}}\right)$ and the refractive index $n$ of the solvents. Irrespective of the empirical scales, straight lines should be obtained while plotting the different graphs, if the selected scale is adapted to describe the solvatochromism.

Table 3. Optical properties of PP5, PP11, PP17, D1-D9 in 23 solvents.

\begin{tabular}{|c|c|c|c|c|c|c|c|c|c|}
\hline compounds & $\pi^{* 1}$ & PP5 $^{2}$ & $\mathbf{P P 6}^{2}$ & PP11 $^{2}$ & $\mathbf{P P 1 7}^{2}$ & D1 $^{2}$ & $\mathbf{D 2}^{2}$ & $\mathbf{D 3}^{2}$ & $\mathrm{D4}^{2}$ \\
\hline acetone & 0.71 & 446 & 558 & 517 & 530 & 471 & 541 & 423 & 431 \\
\hline acetonitrile & 0.75 & 446 & 558 & 509 & 525 & 468 & 541 & 423 & 432 \\
\hline AcOEt & 0.54 & 444 & 542 & 517 & 530 & 467 & 540 & 418 & 431 \\
\hline anisole & 0.73 & 455 & 563 & 536 & 544 & 479 & 551 & 432 & 440 \\
\hline butanol & 0.47 & 461 & 578 & 525 & 556 & 483 & 552 & 435 & 447 \\
\hline chloroform & 0.78 & 458 & 571 & 530 & 550 & 484 & 552 & 439 & 452 \\
\hline cyclohexane & 0.00 & 435 & 525 & 516 & 534 & 459 & 534 & 415 & 429 \\
\hline 1,2-dichloroethane & 0.81 & 453 & 566 & 525 & 543 & 479 & 550 & 429 & 443 \\
\hline dichloromethane & 0.82 & 453 & 568 & 527 & 542 & 478 & 549 & 433 & 445 \\
\hline diethyl carbonate & 0.45 & 440 & 541 & 516 & 532 & 468 & 536 & 420 & 430 \\
\hline diethyl ether & 0.27 & 440 & 527 & 517 & 534 & 461 & 535 & 417 & 430 \\
\hline diglyme & 0.64 & 449 & 560 & 524 & 541 & 476 & 547 & 427 & 438 \\
\hline 1,4-dioxane & 0.55 & 446 & 540 & 516 & 535 & 471 & 537 & 421 & 432 \\
\hline dimethylacetamide & 0.88 & 454 & 573 & 527 & 530 & 479 & 551 & 432 & 437 \\
\hline dimethylformamide & 0.87 & 453 & 574 & 524 & $\mathrm{nd}^{3}$ & 477 & $\mathrm{nd}^{3}$ & 432 & 436 \\
\hline DMSO & 1.00 & 457 & 581 & 526 & 535 & 483 & 551 & 437 & 441 \\
\hline ethanol & 0.54 & 453 & 577 & 522 & 550 & 481 & 548 & 434 & 443 \\
\hline heptane & -0.08 & 434 & 521 & 512 & 533 & 455 & 533 & 411 & 427 \\
\hline nitrobenzene & 1.01 & 460 & 583 & 538 & 551 & 486 & 562 & 441 & 450 \\
\hline THF & 0.58 & 447 & 552 & 520 & 532 & 472 & 545 & 425 & 434 \\
\hline toluene & 0.54 & 450 & 548 & 522 & 539 & 474 & 544 & 428 & 437 \\
\hline triethylamine & 0.14 & 438 & 523 & 526 & $\mathrm{nd}^{3}$ & 462 & $\mathrm{nd}^{3}$ & 419 & 434 \\
\hline$p$-xylene & 0.43 & 448 & 544 & 521 & 540 & 472 & 543 & 426 & 435 \\
\hline
\end{tabular}

${ }^{1}$ Kamlet and Taft parameters ${ }^{2}$ Position of the ICT bands are given in $\mathrm{nm}{ }^{3} \mathrm{nd}:$ not determined

Table 4. Optical properties of PP5, PP11, PP17, D1-D9 in 23 solvents.

\begin{tabular}{|c|c|c|c|c|c|c|c|c|c|}
\hline compounds & $\pi^{* 1}$ & $\mathbf{D 5}^{2}$ & $\mathrm{D6}^{2}$ & $\mathrm{D7}^{2}$ & D8 $^{2}$ & D9 $^{2}$ & $\mathrm{D10}^{2}$ & D11 $^{2}$ & D12 $^{2}$ \\
\hline acetone & 0.71 & 468 & 438 & 439 & 499 & 538 & 526 & 595 & 562 \\
\hline acetonitrile & 0.75 & 466 & 433 & 437 & 499 & 538 & 528 & 597 & 565 \\
\hline AcOEt & 0.54 & 466 & 433 & 435 & 494 & 533 & 520 & 579 & 546 \\
\hline anisole & 0.73 & 475 & 446 & 446 & 504 & 549 & 530 & 599 & 567 \\
\hline butanol & 0.47 & 474 & 442 & 442 & 511 & 542 & $\mathrm{nd}^{3}$ & $\mathrm{nd}^{3}$ & $\mathrm{nd}^{3}$ \\
\hline chloroform & 0.78 & 482 & 447 & 449 & 517 & 554 & 539 & 606 & 574 \\
\hline
\end{tabular}




$\begin{array}{cccccccccc}\text { cyclohexane } & 0.00 & 459 & 429 & 430 & 486 & 516 & 481 & 556 & 532 \\ \text { 1,2-dichloroethane } & 0.81 & 476 & 444 & 445 & 517 & 550 & 536 & 603 & 567 \\ \text { dichloromethane } & 0.82 & 477 & 443 & 446 & 515 & 551 & 537 & 603 & 571 \\ \text { diethyl carbonate } & 0.45 & 464 & 433 & 434 & 487 & 525 & 510 & 575 & 542 \\ \text { diethyl ether } & 0.27 & 466 & \mathrm{nd}^{3} & 431 & 493 & 530 & 502 & 569 & 534 \\ \text { diglyme } & 0.64 & 474 & 431 & 422 & 503 & 544 & 524 & 593 & 567 \\ \text { 1,4-dioxane } & 0.55 & 466 & 434 & 434 & 491 & 529 & 512 & 581 & 545 \\ \text { dimethylacetamide } & 0.88 & 475 & 446 & 447 & 505 & 551 & 543 & 608 & 577 \\ \text { dimethylformamide } & 0.87 & 474 & 446 & 446 & 511 & 546 & 541 & 609 & 579 \\ \text { DMSO } & 1.00 & 478 & 448 & 450 & 513 & 553 & 554 & 620 & 590 \\ \text { ethanol } & 0.54 & 476 & 439 & 441 & 514 & 535 & \mathrm{nd}^{3} & 614 & 581 \\ \text { heptane } & -0.08 & 456 & 427 & 428 & 482 & 513 & 478 & 551 & 529 \\ \text { nitrobenzene } & 1.01 & 486 & 456 & 458 & 528 & 570 & 552 & 613 & 585 \\ \text { THF } & 0.58 & 469 & 440 & 440 & 502 & 539 & 518 & 587 & 555 \\ \text { toluene } & 0.54 & 471 & 440 & 442 & 496 & 531 & 520 & 582 & 553 \\ \text { triethylamine } & 0.14 & \mathrm{nd}^{3} & 432 & 432 & 487 & 522 & 489 & 559 & 533 \\ \quad \text {-xylene } & 0.43 & 470 & 439 & 438 & 496 & 531 & 522 & 580 & 547\end{array}$

${ }^{1}$ Kamlet and Taft parameters ${ }^{2}$ Position of the ICT bands are given in $\mathrm{nm} .{ }^{3}$ nd $:$ not determined

Among the different empirical scales used to examine the solvatochromism of PP5, PP11, PP17, D1-D9, the most adapted ones were determined as being the Catalan and the Kamlet-Taft's scales (See the different graphs in SI). For all the other scales, no straight lines could be obtained and only an aleatory dispersion of points could be obtained. These different graphs are not reported in SI. In the case of the Catalan solvent polarity/polarizability scale, linear correlations were parametrized with three different parameters, namely, the solvent polarizability (SP), the solvent dipolarity (SdP) and the solvent polarity/polarizability (SPP) parameters.[74-76] The different plots can be found in SI. Interestingly, if linear correlations with remarkable values for the square of the correlation coefficients $\left(\mathrm{R}^{2}\right)$ could be obtained for all dyes by plotting the absorption maximum vs. the SPP and the SdP parameters, less favorable correlations were determined with the solvent polarizability (SP) parameter. Indeed, a higher dispersion of points could be detected in the different graphs (See Figures in SI). Therefore, it can be concluded that the solvatochromism of PP5, PP11, D1-D9 is more influenced by the polarity of the solvent than its polarizability. These results were confirmed by the remarkable linear correlations obtained with the Kamlet-Taft's solvent polarity scale (see linear regressions in SI). In several cases, good correlations could also be obtained with the Reichardt polarity scale and an illustration of this is provided in the Figure 9 for compound D3. In light of these results, it can be concluded that the polarity/polarizability of the solvent is the primary cause influencing the position of the ICT bands as it constitutes the basis of the Kamlet-Taft's solvent polarity scale or the Catalan scale while using the polarity/polarizability (SPP) parameter. 
Besides, based on the linear regressions obtained with the Catalan SP parameter that showed lower values of the square of the correlation coefficient $\left(\mathrm{R}^{2}\right)$, it can also be determined that the polarizability strongly influences the solvatochromism. Indeed, the major difference between the SPP and SP parameters relies in the fact that polarity and polarizability are dissociated with the SP parameters, only the polarizability being considered with this parameter. Considering that the SPP parameters can't dissociate polarizability from polarity but that good linear correlations are obtained with the SP parameters that only take into account of the polarizability, it can be assumed that certainly the polarizability strongly contributes to the linear correlations obtained with the SPP parameters. Irrespective of the polarity scales, the negative slopes are indicative of a positive solvatochromism, meaning that a significant charge redistribution occurs upon excitation (See Figure 9).
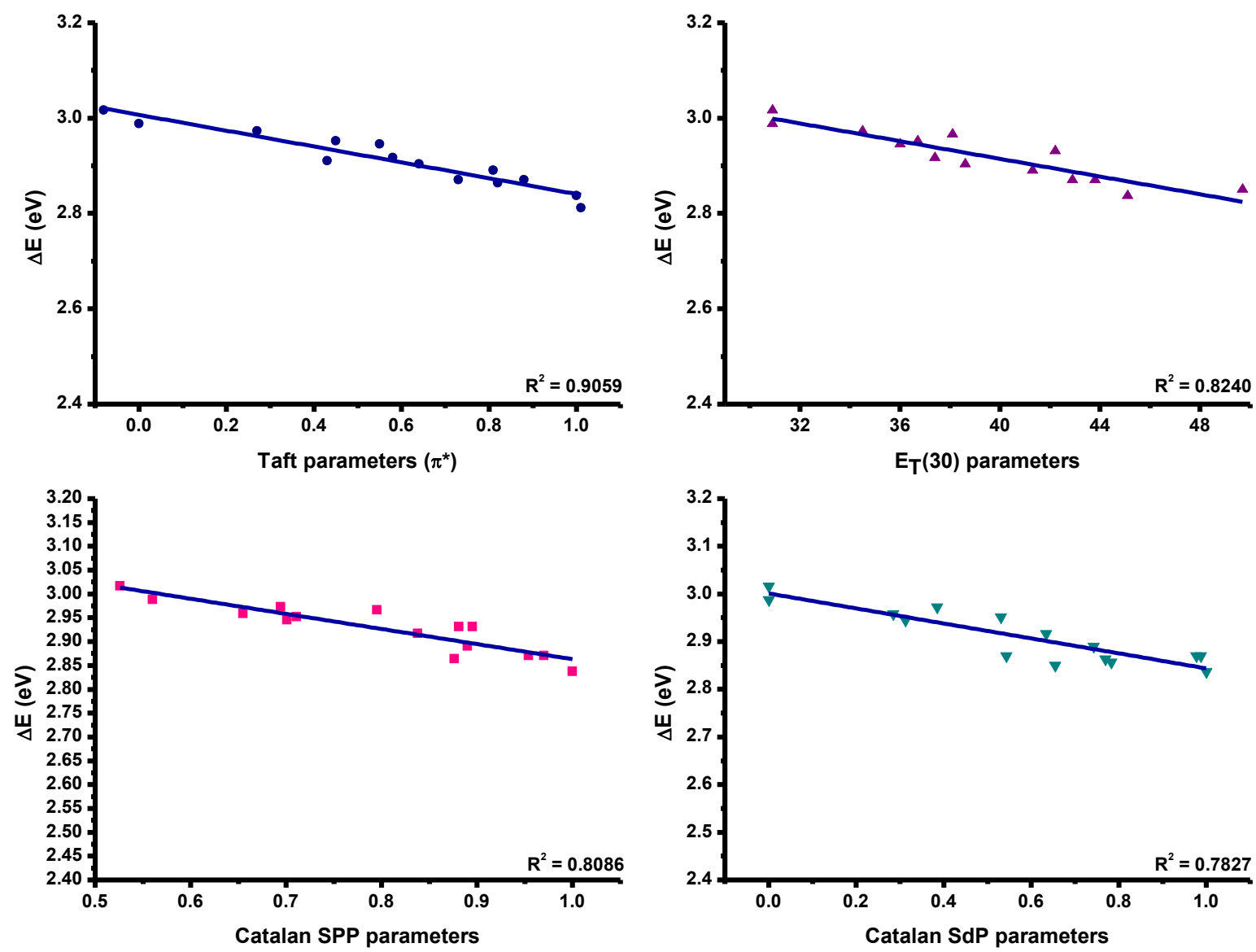

Figure 9. Linear correlations obtained while using four different polarity scales (Kamet-Taft, Catalan and Reichardt scales) for D3. 
In this series, only one dye showed a solvatochromic behavior differing from the others, namely PP17. In this last case, lower linear regressions could be obtained while using the Catalan solvent polarizability (SP) with $\mathrm{R}^{2}=0.708$ or the Reichardt scale $\left(\mathrm{R}^{2}=0.657\right)$ (See Figure 10). This atypical behaviour can be assigned to the presence of numerous $\mathrm{CN}$ groups on the electron acceptor enabling the create hydrogen bonds in high polar solvents. Consequently, the ability for PP17 to create hydrogen bonds with the solvents becomes a primordial parameter, what is parametrized with the polarizability parameters.

a)

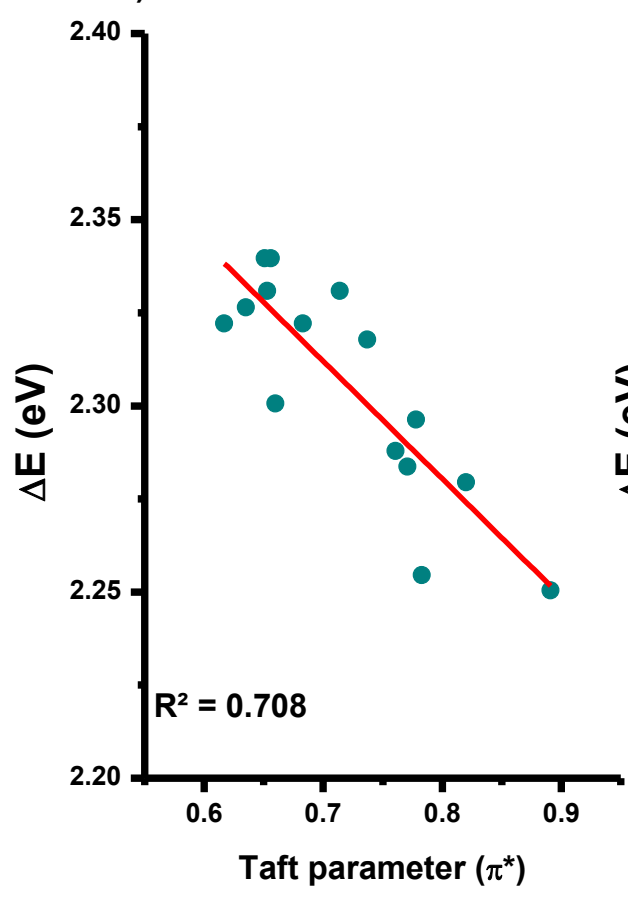

b)

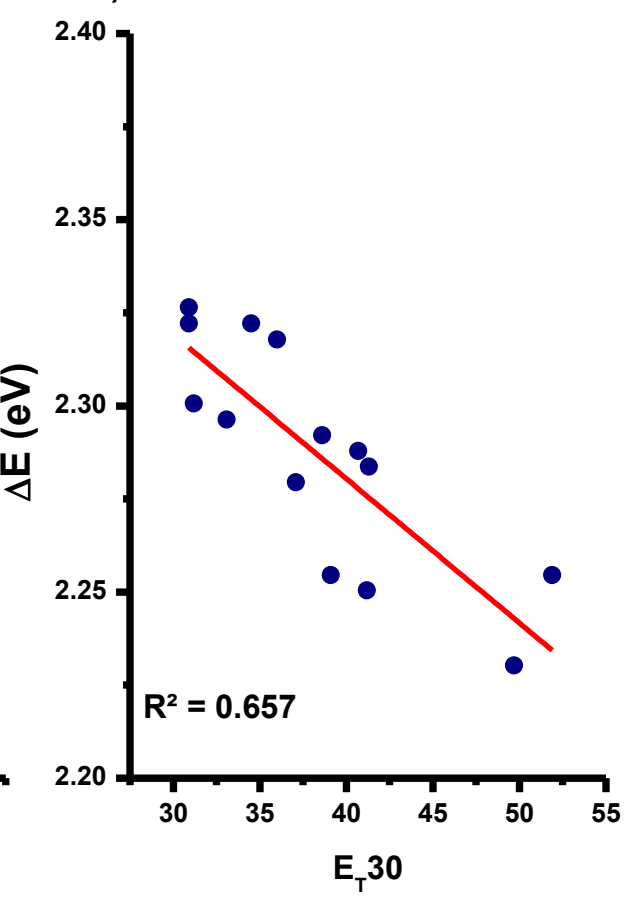

Figure 10. Linear correlations obtained for PP17 while using a) the Kamlet-Taft parameter and b) the Reichardt ( $\left.\mathrm{E}_{\mathrm{T}} 30\right)$ parameter.

Interestingly, while examining the slopes obtained while plotting the HOMO-LUMO gap vs. the Kamlet-Taft parameter, similar slopes could be found for all dyes, demonstrating a similar sensitivity to the solvent polarity (See Figure 11). 


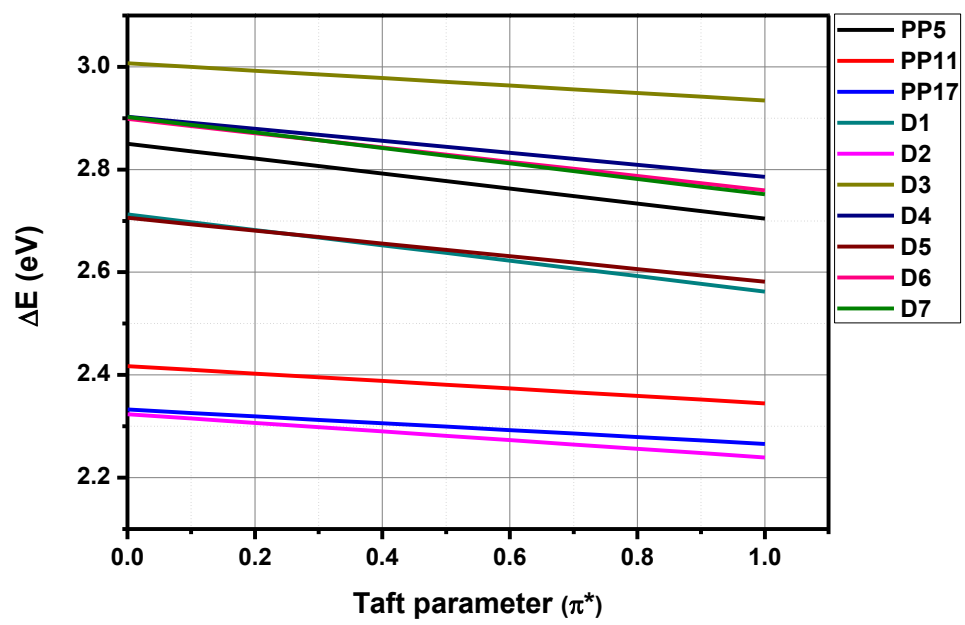

Figure 11. Variation of the positions of the charge transfer band with Kamlet-Taft empirical parameters.

Finally, solvatochromic properties of the references dyes PP6, D10-D12 bearing other electron-donating groups than the 4,4-bis(4-methoxyphenyl)butadienyl donor was also examined. In this last case, the best correlations were obtained with the Kamlet-Taft parameters, enabling to get for the squares of the correlation coefficient $\left(\mathrm{R}^{2}\right)$, values ranging between 0.89 for D12 to 0.98 for D11 (See Figure 12). This is directly related to the higher electron donating ability of ED2-ED4, enabling to give rise to a higher electronic redistribution upon excitation. Finally, examination of the sensitivity to the solvent polarity revealed PP6, D10-D12 to exhibit more negative slopes than the former series (See comparisons between PP6, D10-D12 and PP11 in Figure 13), consistent with the previous conclusions establishing a higher sensitivity to the solvent polarity. Indeed, due to the stronger electron donating groups used to prepare these dyes, a higher sensitivity to the environment and thus the polarity of the solvents can be observed for PP6, D10-D12, resulting in higher shifts of the ICT positions. Variation of the slopes is also related to the molecular structure. Indeed, the largest slopes were obtained for PP6, D10, D11 and D12, all with the stronger dimethylamino donor moiety. Besides, no direct correlation with the dipole moment of the molecule can be established. Indeed, as shown in the Table 5, PP6, D10, D11 and D12 do not exhibit the largest dipole moments of the series of dyes. Indeed, in this field, D8 clearly outperforms the other dyes, with a dipole moment of 20.18 D. 

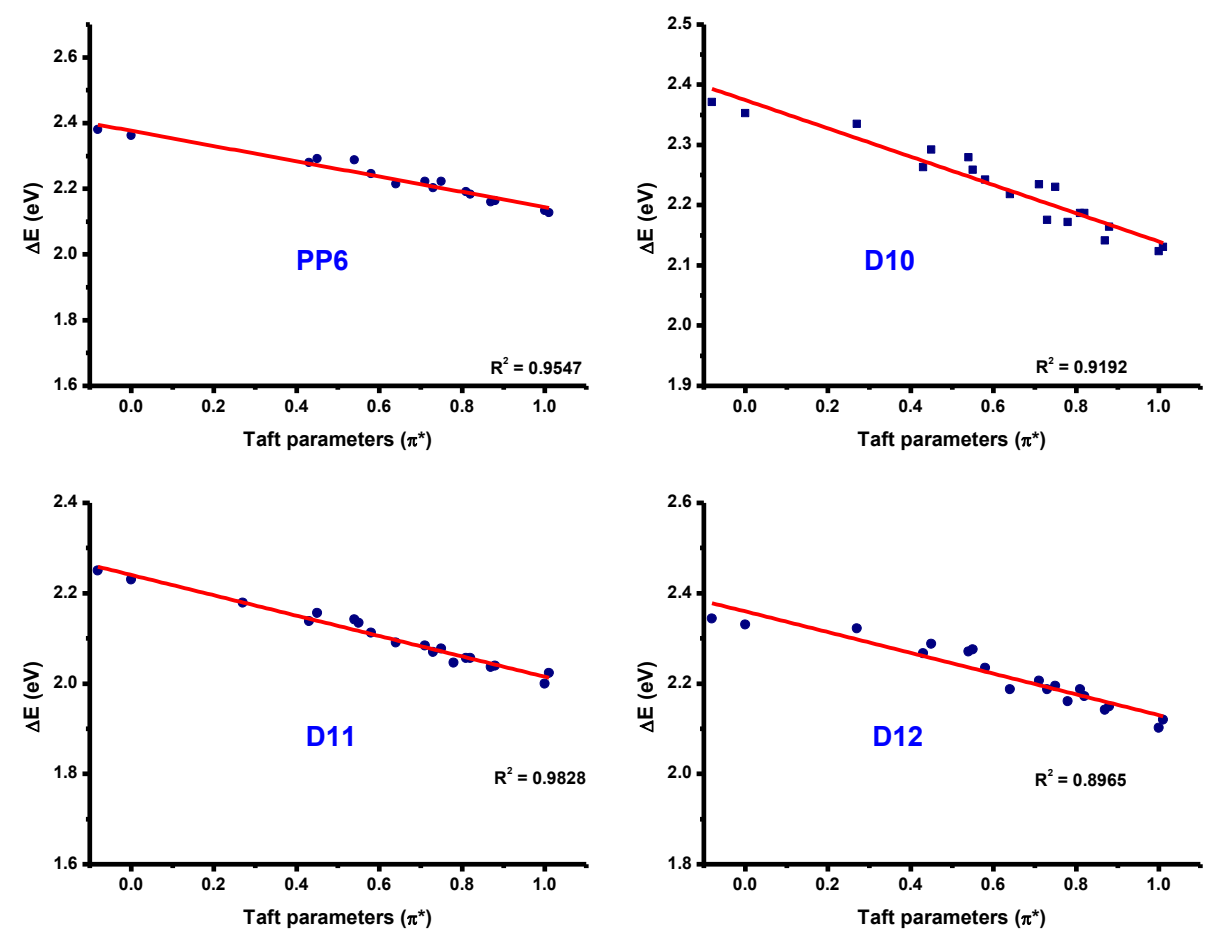

Figure 12. Linear correlations obtained while using the Kamet-Taft solvent polarity scale.

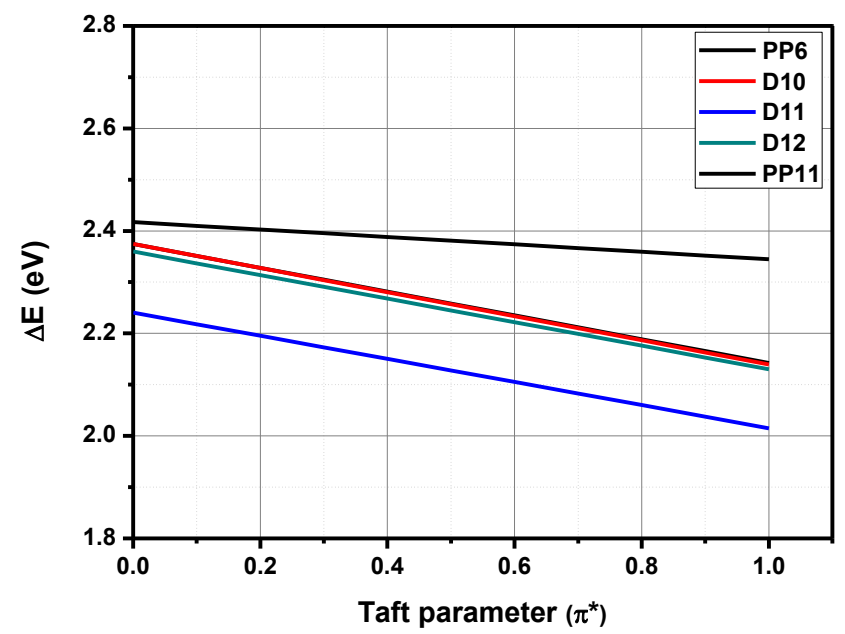

Figure 13. Variation of the positions of the charge transfer band with Kamlet-Taft empirical parameters for PP11, D10-D12.

Table 5. Dipole moment of the different dyes.

\begin{tabular}{|c|c|c|c|c|c|c|}
\hline Compound & PP5 & PP6 & PP11 & PP17 & D1 & D2 \\
\hline $\begin{array}{c}\text { dipole } \\
\text { moment }\end{array}$ & 5.09 & 7.30 & 7.99 & 11.12 & 4.72 & 7.23 \\
\hline Compound & D3 & D4 & D5 & D6 & D7 & D8 \\
\hline $\begin{array}{c}\text { dipole } \\
\text { moment }\end{array}$ & 7.26 & 8.14 & 9.44 & 8.21 & 6.97 & 20.18 \\
\hline
\end{tabular}




\begin{tabular}{|c|c|c|c|c|c|c|}
\hline Compound & D9 & D10 & D11 & D12 & & \\
\hline $\begin{array}{c}\text { dipole } \\
\text { moment }\end{array}$ & 16.56 & 5.45 & 7.30 & 5.16 & & \\
\hline
\end{tabular}

\subsection{Electrochemical properties}

Cyclic voltammetry (CV) has been used to investigate the electrochemical properties of all compounds either in diluted solutions of acetonitrile or in dichloromethane, in function of the solubility of the compounds in acetonitrile. All solutions were deaerated with argon for $10 \mathrm{~min}$ before any $\mathrm{CV}$ measurements. The redox potentials of all compounds are given against the half wave oxidation potential of the ferrocene $(\mathrm{Fc}) /$ ferrocenium cation couple and the different redox potentials are summarized in the Table 6. Along with the redox values are given the HOMO and LUMO energy levels of the different push-pull molecules determined by using as a standard the oxidation potential of $\mathrm{Fc}$, based on the Pommerehne et al. calculations (4.8 eV vs. vacuum).[77]

The dyes were all designed using the same electron-donating group (ED1) which is the reason why almost similar oxidation potentials around $950 \mathrm{mV}$ can be noticed for all dyes. Also, all the oxidation processes are irreversible, corresponding to one electron loss of the central double bound, except in the case of PP17 where a slight reversibility was observed, showing that the acceptor, EA3 which is the strongest electron acceptor of the series might certainly have a small impact on the oxidation process. Furthermore, two exceptions could be found in this set of compounds: D6 and D7 have much lower oxidation potentials than the other pushpulls, about $200 \mathrm{mV}$ less compared to the others, as shown in Figure 14. These two compounds are composed of rhodanine moieties as the electron accepting groups and the DFT calculations have clearly established a high electronic density on the sulfur atoms. An oxidation of these sulfur atoms at lower potentials than the central double bond is then highly probable. Nevertheless, D5 which comprises a thiobarbituric-based electron accepting group also possesses a sulfur atom in its scaffold. However, due to the higher electronic density on this atom in D5 than in D6 and D7, this atom can only be oxidized at much higher potentials. For this reason, D5 oxidizes close to the oxidation potentials of the other dyes with a one irreversible electron process at $1.02 \mathrm{~V}$. 


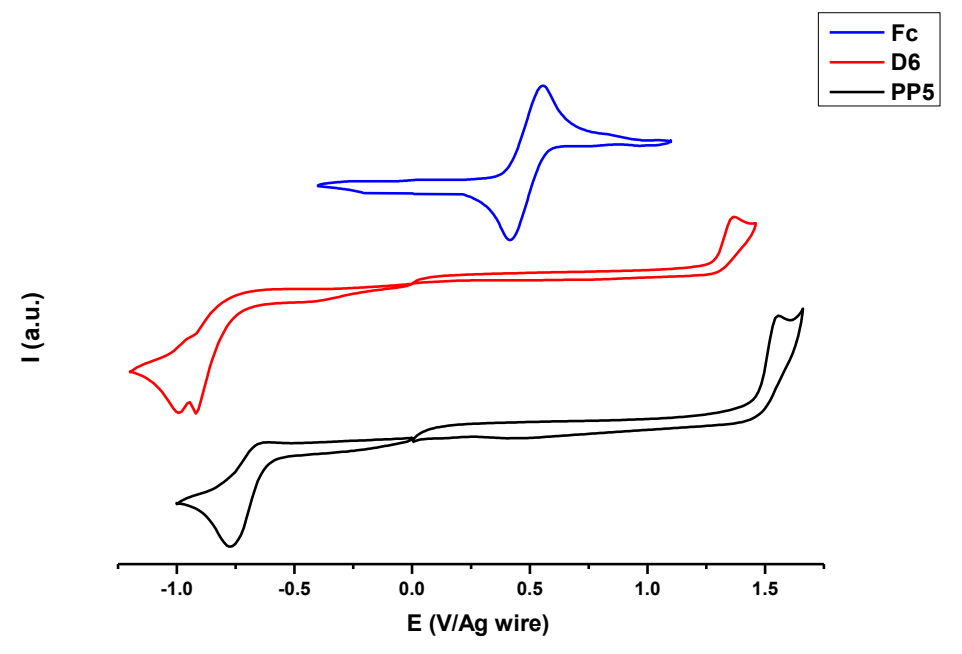

Figure 14. Cyclic voltammograms of PP5, D6 and Ferrocene performed in acetonitrile solutions with tetrabutylammonium perchlorate $(0.1 \mathrm{M})$ as the supporting electrolyte. Scan rate: $100 \mathrm{mV} / \mathrm{s}$.

While getting a deeper insight into the reductions of these compounds, an analogy can be easily made between the electron-withdrawing ability of the acceptor and their reduction potentials. Indeed, the higher the acceptor strength is, the easier the electron acceptor will accept one electron and thus reduce. This capacity is well seen with the different indane derivatives showing easier reduction processes while improving the electron withdrawing ability from PP5 to PP17, as shown in the Figure 15. Parallel to this, elongation of the aromatic core in the indane-based acceptors also improves the accepting properties, as observed for PP11/D2 and for PP5/D1. Addition of one or two dicyanomethylene groups onto the electron acceptors of PP17, PP11 and D2 favored their reduction at higher cathodic potentials than for their analogues D1 and PP5. These observations are consistent with both theoretical calculations where the electronic density is mostly localized onto the acceptor part i.e. the indane moiety. This is also consistent with the optical properties previously discussed where a red shift of the ICT band is observed, resulting from a decrease of the LUMO energy level. [37,45] In addition, we can highlight the fact that the two most cathodic reduction potentials are found for the two rhodamine derivatives, with almost similar values. This observation proves two phenomena: the fact that the addition of the allyl group has no impact on the accepting ability of the rhodamine group and that rhodanines are extremely weak electron acceptors, in accordance with the observations of their low oxidation potentials. Usually, for push-pull dyes, the HOMO energy level is localized onto the electron donor and the LUMO level is centered onto the accepting moiety. Oppositely, for D6 and D7, an unusual repartition of the two orbitals was 
observed by $\mathrm{CV}$ and this unexpected behavior was also demonstrated by DFT calculations, the two orbitals extending over the whole molecule. This particularity was also confirmed by the position of their ICT bands greatly differing from that of the other dyes.
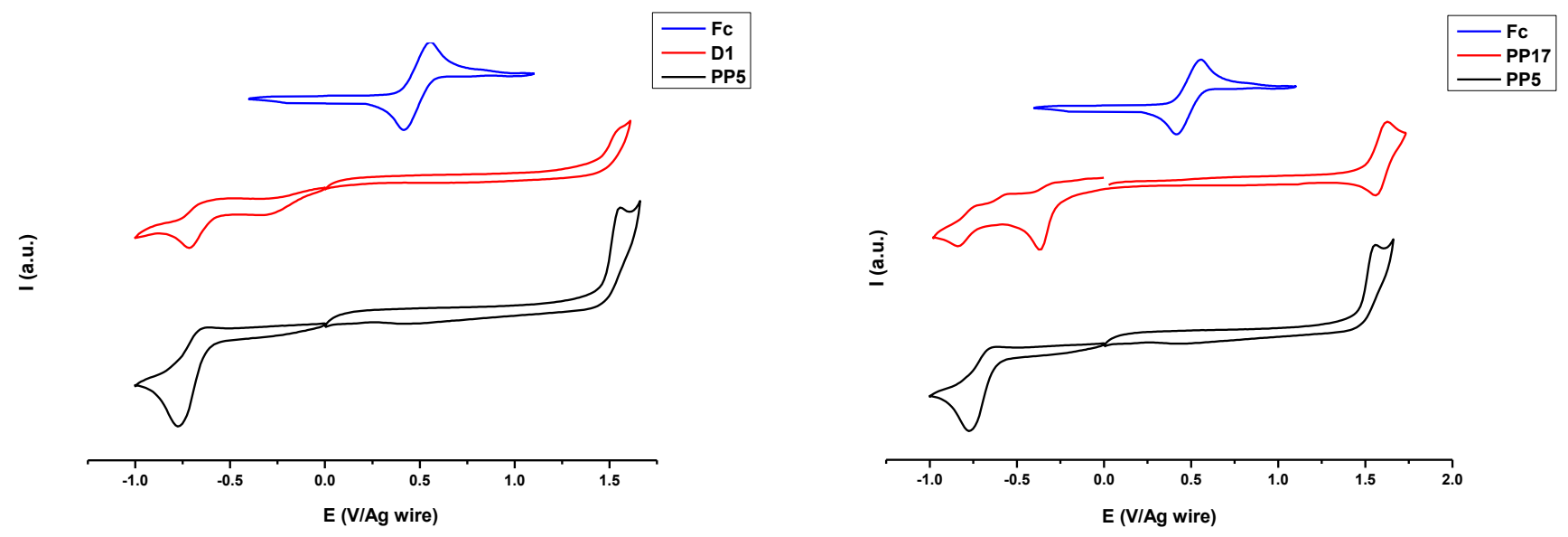

Figure 15. Selected cyclic voltammograms of PP5, PP17, D1 and Ferrocene performed in acetonitrile solutions with tetrabutylammonium perchlorate $(0.1 \mathrm{M})$ as the supporting electrolyte. Scan rate: $100 \mathrm{mV} / \mathrm{s}$.

Finally, position of the HOMO and LUMO energy levels could be determined for all dyes. Even though the equations proposed by Pommerehne et al. was used, other methods reported in the literature may be mentioned to determine these values such as the equations developed by Cardona et al.[78] Indeed, Figure 16 shows a comparison between the frontier orbital energy levels obtained by $\mathrm{CV}$ and the energy levels determined by DFT calculations. These data allow us to highlight a few points. Despite a good correlation between CV, UVvisible measurements and DFT calculations, some molecules are better "predicted" than the others. In fact, theoretical values determined for the HOMO energy levels perfectly fit with those determined by cyclic voltammetry with only two exceptions, namely D8 and D9 comprising EA11 and EA12 as the electron acceptors. To support these variations, and by taking a closer look into the shape of their HOMO orbitals, a higher delocalization of the electronic density can be found for these two dyes compared to the others, which may explain the higher influence of the solvent on the determination of the HOMO position. Indeed, CV measurements were not performed in the same solvent than that used for the theoretical calculations, simply due to the fact that acetonitrile offers a wider electrochemical window than dichloromethane. Finally, considering that the solvent can impact the position of the HOMO energy level, a comparison between the optical and theoretical bandgap in dichloromethane was established. Parallel to this, a comparison between the optical and electrochemical bandgap in 
acetonitrile is also provided. As shown in the Figure 17, high differences can be found between the values determined by cyclic voltammetry and absorption spectroscopy. Conversely, a good adequation between the values determined by DFT and absorption spectroscopy can be found. It can be then concluded that $\Delta \mathrm{E}$ determined by $\mathrm{CV}$ is clearly underestimated. This underestimation can be assigned to the difficulty to clearly determine on the cyclic voltammograms the exact positions of the intersection points of the tangents for the oxidation and the reduction potentials. Still differing from the other dyes, a perfect match between the theoretical and optical bandgap could be found for D6 and D7 comprising the rhodanine moiety. Indeed, if a difference of about $0.3 \mathrm{eV}$ between the DFT and optical bandgaps can be found for all dyes, this difference is reduced to only $0.1 \mathrm{eV}$ for D6 and D7. An opposite trend was found while comparing the electrochemical and optical bandgaps. In this case, the worse mismatch between the two values can be found for these two compounds. As previously mentioned, D6 and $\mathbf{D 7}$ drastically differ from the other dyes by their electronic distributions of the HOMO and LUMO energy levels so that a dramatic influence of the solvent on the positions of these two orbitals can be found.

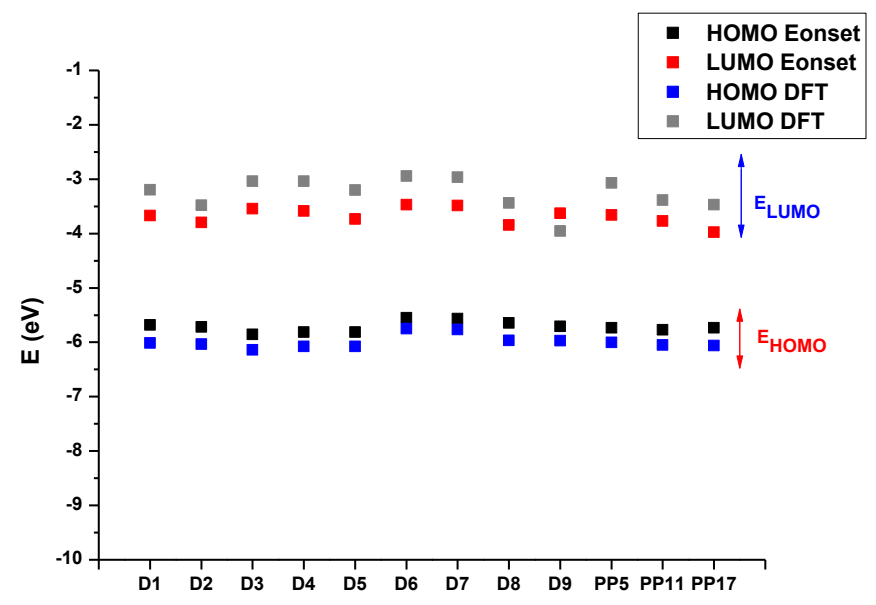

Figure 16. Comparisons between the frontier orbitals' energy levels estimated in acetonitrile by DFT calculations and those obtained by cyclic voltammetry in acetonitrile. 

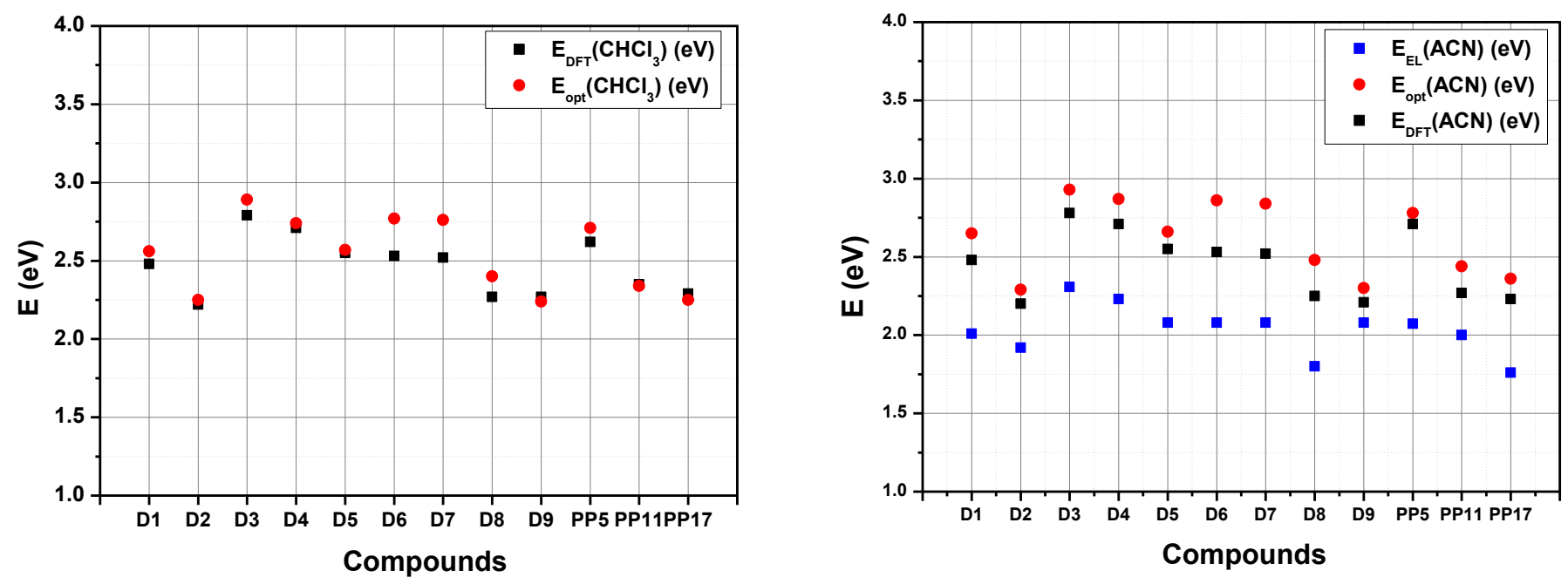

Figure 17. Left: comparisons between the optical determined in chloroform by UV-visible absorption spectroscopy and the theoretical bandgap determined in chloroform by DFT calculations. Right: comparisons of the optical bandgaps determined by UV-visible spectroscopy in acetonitrile, the bandgaps obtained by cyclic voltammetry and theoretical calculations in the same solvent.

Table 6. Summary of the bandgaps determined by UV-visible absorption spectroscopy, cyclic

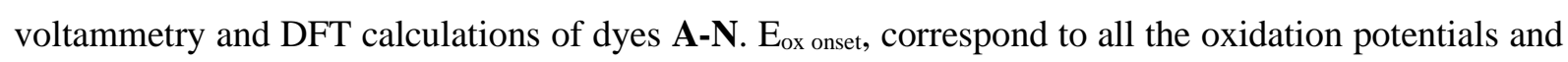
$\mathrm{E}_{\text {red onset }}$ the reduction potentials. $\Delta \mathrm{E}_{\mathrm{el}}$ corresponds to the difference between the HOMO and the LUMO levels, electrochemically obtained. $\Delta \mathrm{E}_{\mathrm{opt}}$ are calculated from UV bands in different solvents. Finally, $\Delta \mathrm{E}_{\text {th }}$ is the difference between the HOMO and LUMO levels, theoretically obtained. $\mathrm{Fc} / \mathrm{Fc}^{+}$was used as internal reference standard.

\begin{tabular}{|c|c|c|c|c|c|c|c|c|c|}
\hline Compounds & $\begin{array}{l}E_{\text {ox onset }} \\
(\mathrm{V} / \mathrm{Fc})\end{array}$ & $\begin{array}{l}\mathrm{E}_{\text {red onset }} \\
(\mathrm{V} / \mathrm{Fc})\end{array}$ & $\begin{array}{c}\text { E }_{\text {HOMO }} \\
(\mathrm{eV})\end{array}$ & $\begin{array}{c}\text { E }_{\text {LUMO }} \\
(\mathrm{eV})\end{array}$ & $\begin{array}{c}\Delta \mathrm{E}_{\text {elACN }} \\
(\mathrm{eV})^{1}\end{array}$ & $\begin{array}{c}\Delta \mathrm{E}_{\text {thACN }} \\
(\mathrm{eV})^{2}\end{array}$ & $\begin{array}{c}\Delta \mathrm{E}_{\text {thCHCl3 }} \\
(\mathrm{eV})^{3}\end{array}$ & $\begin{array}{c}\Delta \mathrm{E}_{\text {opt ACN }} \\
(\mathrm{eV})^{4}\end{array}$ & $\begin{array}{c}\Delta \mathrm{E}_{\text {opt CHCl3 }} \\
(\mathrm{eV})^{5}\end{array}$ \\
\hline D1 & 0.88 & -1.13 & -5.68 & -3.67 & 2.01 & 2.48 & 2.48 & 2.65 & 2.56 \\
\hline D2 & 0.92 & -1.00 & -5.72 & -3.80 & 1.92 & 2.20 & 2.22 & 2.29 & 2.25 \\
\hline D3 & 1.05 & -1.26 & -5.85 & -3.55 & 2.31 & 2.78 & 2.79 & 2.93 & 2.89 \\
\hline D4 & 1.01 & -1.22 & -5.81 & -3.58 & 2.23 & 2.71 & 2.71 & 2.87 & 2.74 \\
\hline D5 & 1.02 & -1.07 & -5.82 & -3.74 & 2.08 & 2.55 & 2.55 & 2.66 & 2.57 \\
\hline D6 & 0.75 & -1.33 & -5.55 & -3.47 & 2.08 & 2.53 & 2.53 & 2.86 & 2.77 \\
\hline D7 & 0.76 & -1.32 & -5.56 & -3.48 & 2.08 & 2.52 & 2.52 & 2.84 & 2.76 \\
\hline D8 & 0.84 & -0.96 & -5.64 & -3.84 & 1.80 & 2.25 & 2.27 & 2.48 & 2.40 \\
\hline D9 & 0.91 & -1.17 & -5.71 & -3.63 & 2.08 & 2.21 & 2.27 & 2.30 & 2.24 \\
\hline PP5 & 0.93 & -1.14 & -5.73 & -3.66 & 2.07 & 2.71 & 2.62 & 2.78 & 2.71 \\
\hline PP11 & 0.97 & -1.03 & -5.77 & -3.77 & 2.00 & 2.27 & 2.35 & 2.44 & 2.34 \\
\hline PP17 & 0.94 & -0.83 & -5.74 & -3.98 & 1.76 & 2.23 & 2.29 & 2.36 & 2.25 \\
\hline
\end{tabular}


of 4.9 was used for the theoretical calculations ${ }^{4}$ Optical bandgaps determined in ACN ${ }^{5}$ Optical bandgaps determined in $\mathrm{CHCl}_{3}$

\section{Conclusion}

In conclusion, a series of 12 dyes strongly absorbing in the visible range have been synthesized using a weak electron-donor and examined for their photophysical properties. As anticipated, a redshift of the absorption maxima with the acceptor strength was logically observed, enabling the ICT to shift from 447 to $606 \mathrm{~nm}$ in chloroform. Examination of their solvatochromism revealed that the different empirical models based on the polarity/polarizability of the solvents could perfectly support the solvatochromism observed experimentally. CV measurements allowed to correlate the trend observed by UV-visible spectroscopy, with a stabilization of the LUMO levels by improving the accepting strength. By electrochemistry, a reduction of these compounds at less cathodic potentials upon improvement of the electron strength was clearly observed. Unusual electrochemical behaviors detected for D5 and D6 were supported by DFT calculations evidencing a distribution of both the HOMO and LUMO energy level over the whole molecule. By combining complementary techniques such as UV-visible absorption spectroscopy, DFT calculations and cyclic voltammetry, a better understanding of the photophysical properties could be obtained. Considering their high molar extinction coefficients in solution, some dyes such as PP5, D4 or D7 are ideal candidates for applications in organic solar cells. However, their absorptions in thin films, especially when mixed with an electron acceptor such as [6,6]-phenyl- $\mathrm{C}_{61}$-butyric acid methyl ester $\left(\mathrm{PC}_{61} \mathrm{BM}\right)$, the nanostructuration in bulk heterojunctions have still to be examined.[79-81] Parallel to this, panchromatic dyes are also actively researched for photopolymerization applications. In this field, PP6, D9 and D10 by their broad absorption spectra extending over the visible range are perfect candidates and polymerization tests for the free radical polymerization of acrylates or the cationic polymerization of epoxides under low light intensity and even for sunlight-induced polymerization will be reported in forthcoming works. However, the absorption properties of dyes are not the only parameters governing the polymerization efficiencies.[19,20] Notably, the rate constants of interactions with the different additives introduced in the three-component photoinitiating systems, the possibility of back electron transfer between the excited photosensitizers and the additives, or the solubility of dyes in monomers cannot be anticipated at this stage so that comparisons with benchmark systems have to be precluded. 


\section{Acknowledgments}

The authors thank Aix Marseille University and The Centre National de la Recherche Scientifique (CNRS) for financial supports. The Agence Nationale de la Recherche (ANR agency) is acknowledged for its financial support through the $\mathrm{PhD}$ grants of Corentin Pigot (ANR-17-CE08-0010 DUALITY project) and Guillaume Noirbent (ANR-17-CE08-0054 VISICAT project).

\section{References}

[1] Chou, P.-T.; Chi, Y. Phosphorescent dyes for organic light-emitting diodes, Chem. Eur. J. 2007;13:380-395.

[2] Redon, S.; Eucat, G.; Ipuy, M.; Jeanneau, E.; Gautier-Luneau, I.; Ibanez, A.; Andraud, C.; Bretonnière, Y.; Tuning the solid-state emission of small push-pull dipolar dyes to the far-red through variation of the electron-acceptor group, Dyes Pigm. 2018;156:116132.

[3] Hancock, J.M.; Gifford, A.P.; Zhu, Y.; Lou, Y. Jenekhe, S.A. n-Type conjugated oligoquinoline and oligoquinoxaline with triphenylamine endgroups: efficient ambipolar light emitters for device applications, Chem. Mater. 2006;18:4924-4932.

[4] Farré, Y.; Raissi, M.; Fihey, A.; Pellegrin, Y.; Blart, E.; Jacquemin, D.; Odobel, F. Synthesis and properties of new benzothiadiazole-based push-pulldyes for p-type dye sensitized solar cells, Dyes Pigm. 2018;148:154-166.

[5] Parsa, Z.; Shahab Naghavi, S.; Safari, N. Designing push-pull porphyrins for efficient dye-sensitized solar cells, J. Phys. Chem. A 2018;122:5870-5877.

[6] Yella, A.; Mai, C.-L.; Zakeeruddin, S.M.; Chang, S.-N.; Hsieh, C.-H.; Yeh, C.-Y.; Graetzel, M. Molecular engineering of push-pull porphyrin dyes for highly efficient dye-sensitized solar cells: the role of benzene spacers, Angew. Chem. Int. Ed. 2014;53:2973-2977.

[7] Huo, F.; Zhang, H.; Chen, Z.; Qiu, L.; Liu, J.; Bo, S.; Kityk, I.V. Novel nonlinear optical push-pull fluorene dyes chromophore as promising materials for telecommunications, J. Mater. Sci. Mater. Electron. 2019;30:12180-12185.

[8] Raimundo, J.M.; Blanchard, P.; Gallego-Planas, N.; Mercier, N.; Ledoux-Rak, I.; Hierle, R.; Roncali, J. Design and synthesis of push-pull chromophores for second-order 
nonlinear optics derived from rigidified thiophene-based-conjugating spacers, J. Org. Chem. 2002;67:205-218.

[9] Mohammed, N.; Wiles, A.A.; Belsley, M.; Fernandes, S.S.M.; Cariello, M.; Rotello, V.M.; Raposo, M.M.M.; Cooke, G. Synthesis and characterisation of push-pull flavin dyes with efficient second harmonic generation (SHG) properties, RSC Adv. 2017;7:24462-24469.

[10] Thooft, A.M.; Cassaidy, K.; Van Veller, B. A small push-pull fluorophore for turn-on fluorescence, J. Org. Chem. 2017;82:8842-8847.

[11] Karpenko, I.A.; Niko, Y.; Yakubovskyi, V.P.; Gerasov, A.O.; Bonnet, D.; Kovtun, Y.P.; Klymchenko, A.S. Push-pull dioxaborine as fluorescent molecular rotor: far-red fluorogenic probe for ligand-receptor interactions, J. Mater. Chem. C 2016;4:30023009 .

[12] Xiao, P.; Dumur, F.; Bui, T.-T.; Sallenave, X.; Goubard, F.; Graff, B.; Morlet-Savary, F.; Fouassier, J.-P.; Gigmes, D.; Lalevée, J. Panchromatic photopolymerizable cationic films using indoline and squaraine dyes based photoinitiating systems, ACS MacroLetters 2013;2:736-740.

[13] Tehfe, M.-A.; Dumur, F.; Vilà, N.; Graff, B.; Mayer, C.R.; Fouassier, J.-P.; Gigmes, D.; Lalevée, J. A multicolor photoinitiator for cationic polymerization and interpenetrated polymer network synthesis: 2,7-di-tert-butyldimethyl-dihydropyrene, Macromol. Rapid Commun. 2013;34:1104-1109.

[14] Xiao, P.; Dumur, F.; Thirion, D.; Fagour, S.; Vacher, A.; Sallenave, X.; Graff, B.; Fouassier, J.-P.; Gigmes, D.; Lalevée, J. Multicolor photoinitiators for radical and cationic polymerization: mono vs. poly functional thiophene derivatives, Macromolecules 2013;46:6786-6793.

[15] Tehfe, M.-A.; Dumur, F.; Graff, B.; Morlet-Savary, F.; Gigmes, D.; Fouassier, J.-P.; Lalevée, J. Push-pull (thio)barbituric acid derivatives in dye photosensitized radical and cationic polymerization reactions under 457/473 nm Laser beams or blue LEDs, Polym. Chem. 2013;4:3866-3875.

[16] Xiao, P.; Dumur, F.; Graff, B.; Vidal, L.; Gigmes, D.; Fouassier, J.-P.; Lalevée, J. Structural effects in the indanedione skeleton for the design of low intensity 300-500 nm light sensitive initiators, Macromolecules 2014;47:26-34. 
[17] Xiao, P.; Dumur, F.; Tehfe, M.-A.; Gigmes, D.; Fouassier, J.-P.; Lalevée, J. Red-lightinduced cationic photopolymerization: perylene derivatives as efficient photoinitiators, Macromol. Rapid. Commun. 2013;34:1452-1458 .

[18] Al Mousawi, A.; Poriel, C.; Dumur, F.; Toufaily, J.; Hamieh, T.; Fouassier, J.-P.; Lalevée, J. Zinc tetraphenyl-porphyrin as high performance visible-light photoinitiator of cationic photosensitive resins for LED projector $3 \mathrm{D}$ printing applications, Macromolecules 2017;50:746-753.

[19] Pigot, C.; Noirbent, G.; Brunel, D.; Dumur, F. Recent advances on push-pull organic dyes as visible light photoinitiators of polymerization, Eur. Polym. J. 2020;133:109797.

[20] Dumur, F. Recent advances on visible light photoinitiators of polymerization based on indane-1,3-dione and related derivatives, Eur. Polym. J. 2021;143:110178.

[21] Lalevée, J.; Fouassier, J.-P. Recent advances in sunlight induced polymerization: role of new photoinitiating systems based on the silyl radical chemistry, Polym. Chem., 2011;2:1107-1113.

[22] Tehfe, M.-A.; Lalevée, J.; Gigmes, D.; Fouassier, J.-P. Green Chemistry: SunlightInduced Cationic Polymerization of Renewable Epoxy Monomers Under Air, Macromolecules 2010;43:1364-1370.

[23] Sun, K.; Liu, S.; Chen, H.; Morlet-Savary, F.; Graff, B.; Pigot, C.; Nechab, M.; Xiao, P.; Dumur, F.; Lalevée, J. N-ethylcarbazole-1-allylidene-based push-pull dyes as efficient light harvesting photoinitiators for sunlight induced polymerization, Eur. Polym. J. 2021;147:110331.

[24] Tehfe, M.-A.; Louradour, F.; Lalevée, J.; Fouassier, J.-P. Photopolymerization Reactions: On the Way to a Green and Sustainable Chemistry, Appl. Sci. 2013;3:490514.

[25] Lalevée, J.; Mokbel, H.; Fouassier, J.-P. Recent Developments of Versatile Photoinitiating Systems for Cationic Ring Opening Polymerization Operating at Any Wavelengths and under Low Light Intensity Sources, Molecules 2015;20:7201-7221.

[26] Dietlin, J.; Schweizer, S.; Xiao, P.; Zhang, J.; Morlet-Savary, F.; Graff, B.; Fouassier, J.-P.; Lalevée, J. Photopolymerization upon LEDs: new photoinitiating systems and strategies, Polym. Chem. 2015;6:3895-3912. 
[27] Ravelli, D.; Fagnoni, M. Dyes as visible light photoredox organocatalysts, ChemCatChem 2012;4:169-171.

[28] Le, T.; Courant, T.; Merad, J.; Allain, C.; Audebert, P.; Masson, G. s-Tetrazine dyes: A facile generation of photoredox organocatalysts for routine oxidations, J. Org. Chem. 2019;84:16139-16146.

[29] Fidaly, K.; Ceballos, C.; Falguières, A.; Sylla-Iyarreta Veitia, M.; Guy, A.; Ferroud, C. Visible light photoredox organocatalysis: a fully transition metal-free direct asymmetric $\alpha$-alkylation of aldehydes, GreenChem. 2012;14:1293-1297.

[30] da Gama Oliveira, V.; Filomena do Carmo Cardoso, M.; da Silva Magalhães Forezi, L. Organocatalysis: A brief overview on its evolution and applications, Catalysts 2018;8:605.

[31] Bureš, F. Fundamental aspects of property tuning in push-pull molecules, RSC Adv. 2014;4:58826-58851.

[32] Kulhanek, J.; Bures, F.; Pytela, O.; Mikysek, T.; Ludvıkc, J.; Ruzicka, A. Push-pull molecules with a systematically extended p-conjugated system featuring 4,5dicyanoimidazole, Dyes Pigm. 2010;85:57-65.

[33] Kuhn, H. Oscillator strength of absorption band in dye molecules, J. Chem. Phys. 1958;29:958.

[34] Feng, J.; Jiao, Y.; Ma, W.; Nazeeruddin, M.K.; Grätzel, M.; Meng, S. First principles design of dye molecules with ullazine donor for dye sensitized solar cells, J. Phys. Chem. C 2013;117:3772-3778.

[35] Thomas, R.; Thomas, A.; Pullanchery, S.; Joseph, L.; Mambully Somasundaran, S.; Srinivasamurthy Swathi, R.; Gray, S.K.; George Thomas, K. Plexcitons: The role of oscillator strengths and spectral widths in determining strong coupling ACS Nano 2018;12:402-415.

[36] Francos, J.; Borge, J.; Diez, J.; Garcia-Garrido, S.E.; Cadierno, V. Easy entry to donor/acceptor butadiene dyes through a MW-assisted $\mathrm{InCl} 3$-catalyzed coupling of propargylic alcohols with indan-1,3-dione in water Catal. Commun. 2015;63:10-14. 
[37] Francos, J.; Garcia-Garrido, S.E.; Borge, J.; Suarez, F.J.; Cadierno, V. Butadiene dyes based on 3-(dicyano-methylidene)indan-1-one and 1,3-bis(dicyanomethylidene)indane: synthesis, characterization and solvatochromic behavior, RSC Adv. 2016;6:6858-6867.

[38] Barnsley, J.E.; Pelet, W.; McAdam, J.; Wagner, K.; Hayes, P.; Officer, D.L.; Wagner, P.; Gordon, K.C. When "donor-acceptor" dyes delocalize: A spectroscopic and computational study of D-A dyes using "Michler's Base", J. Phys. Chem. A 2019;123:5957-5968.

[39] Cadierno, V. (E)-1,1,1-Trifluoro-6,6-bis(4-methoxyphenyl)hexa-3,5-dien-2-one, Molbank 2020;2020:M1120.

[40] Dumur, F.; Mayer, C.R.; Dumas, E.; Miomandre, F.; Frigoli, M.; Sécheresse, F. New chelating stilbazonium like dyes from Michler's ketone, Org. Lett. 2008;10:321-324.

[41] Tehfe, M.-A.; Dumur, F.; Graff, B.; Morlet-Savary, F.; Gigmes, D.; Fouassier, J.-P.; Lalevée, J. New push-pull dyes derived from Michler's ketone for polymerization reactions upon visible lights, Macromolecules 2013;46:3761-3770.

[42] Mokbel, H.; Dumur, F.; Graff, B.; Gigmes, D.; Mayer, C.R.; Toufaily, J.; Hamieh, T.; Fouassier, J.-P.; Lalevée, J. Michler's ketone as an interesting scaffold for the design of high-performance dyes in photoinitiating systems upon visible lights, Macromol. Chem. Phys. 2014;215:783-790.

[43] Noirbent, G.; Dumur, F. Recent advances on nitrofluorene derivatives: Versatile electron acceptors to create dyes absorbing from the visible to the near and far infrared region, Materials 2018;11:2425.

[44] Knoevenagel, E. Ueber eine Darstellungsweise des Benzylidenacetessigesters, Ber. Dtsch. Chem. Ges. 1896;29:172-174.

[45] Pigot, C.; Noirbent, G.; Peralta, S.; Duval, S.; Bui, T.-T.; Aubert, P.-H.; Nechab, M.; Gigmes, D.; Dumur, F. New push-pull dyes based on 2-(3-oxo-2,3-dihydro-1Hcyclopenta[b]naphthalen-1-ylidene)malononitrile: An amine-directed synthesis, Dyes Pigm. 2020;175:108182.

[46] Pigot, C.; Noirbent, G.; Peralta, S.; Duval, S.; Nechab, M.; Gigmes, D.; Dumur, F. Unprecedented nucleophilic attack of piperidine on the electron acceptor during the 
synthesis of push-pull dyes by a knoevenagel reaction, Helv. Chim. Acta 2019;102:e1900229.

[47] Landmesser, T.; Linden, A.; Hansen, H.-J.; A novel route to 1-substituted 3(dialkylamino)-9-oxo-9H-indeno[2,1-c]-pyridine-4-carbonitriles. Helv. Chim. Acta 2008;91:265-284.

[48] Helmy, S.; Oh, S.; Leibfarth, F.A.; Hawker, C.J.; Read de Alaniz, J. Design and synthesis of donor-acceptor Stenhouse adducts: a visible light photoswitch derived from furfural. J. Org. Chem. 2014;79:11316-11329.

[49] Gao, M.; Su, H.; Lin, Y.; Ling, X.; Li, S.; Qin, A.; Zhong Tang, B. Photoactivatable aggregation-induced emission probes for lipid droplets-specific live cell imaging, Chem. Sci. 2017;8:1763-1768.

[50] Cui, Y.; Ren, H.; Yu, J.; Wang, Z.; Qian, G; An indanone-based alkoxysilane dye with second order nonlinear optical properties, Dyes Pigm. 2009;81:53-57.

[51] Yang, X.; Fox, T.; Berke, H. Synthetic and mechanistic studies of metal-free transfer hydrogenations applying polarized olefins as hydrogen acceptors and amine borane adducts as hydrogen donors, Org. Biomol. Chem. 2012;10:852-860.

[52] Pigot, C.; Noirbent, G.; Bui, T.-T.; Peralta, S.; Duval, S.; Gigmes, D.; Nechab, M.; Dumur, F. Synthesis, optical and electro-chemical properties of a series of push-pull dyes based on the 4-(9-ethyl-9H-carbazol-3-yl)-4-phenylbuta-1,3-dienyl donor, New J. Chem. (2021) 10.1039/D1NJ00275A

[53] Pigot, C.; Noirbent, G.; Peralta, S.; Duval, S.; Nechab, M.; Gigmes, D.; Dumur, F. Unprecedented nucleophilic attack of piperidine on the electron acceptor during the synthesis of push-pull dyes by a knoevenagel reaction, Helv. Chim. Acta 2019;102:e1900229.

[54] Cao, C.; Zhou, X.; Xue, M.; Han, C.; Feng, W.; Li, F. Dual near-infrared-emissive luminescent nanoprobes for ratiometric luminescent monitoring of $\mathrm{ClO}^{-}$in living organisms, ACS Appl. Mater. Interf. 2019;11:15298-15305.

[55] Perepichka, D.F.; Perepichka, I.F.; Ivasenko, O.; Moore, A.J.; Bryce, M.R.; Kuzmina, L.G.; Batsanov, A.S.; Sokolov, N.I. Combining high electron affinity and 
intramolecular charge transfer in 1,3-dithiole-nitrofluorene push-pull diads, Chem. Eur. J. 2008;14:2757-2770.

[56] Pavelyev, V.G.; Parashchuk, O.D.; Krompiec, M.; Orekhova, T.V.; Perepichka, I.F.; van Loosdrecht, P.H.M.; Paraschuk, D.Y.; Pshenichnikov, M.S. Charge transfer dynamics in donor-acceptor complexes between a conjugated polymer and fluorene acceptors, J. Phys. Chem. C 2014;118:30291-30301.

[57] Frisch, M.J.; Trucks, G.W.; Schlegel, H.B.; Scuseria, G.E.; Robb, M.A.; Cheeseman, J.R.; Montgomery, Jr., J.A.; Vreven, T.; Kudin, K.N.; Burant, J.C.; Millam, J.M.; Iyengar, S.S.; Tomasi, J.; Barone, V.; Mennucci, B.; Cossi, M; Scalmani, G.; Rega, N.; Petersson, G.A.; Nakatsuji, H.; Hada, M.; Ehara, M.; Toyota, K.; Fukuda, R.; Hasegawa, J.; Ishida, M.; Nakajima, T.; Honda, Y.; Kitao, O.; Nakai, H.; Klene, M.; Li, X.; Knox, J.E.; Hratchian, H.P.; Cross, J.B.; Bakken, V.; Adamo, C.; Jaramillo, J.; Gomperts, R.; Stratmann, R.E.; Yazyev, O.; Austin, A.J.; Cammi, R.; Pomelli, C.; Ochterski, J.W.; Ayala, P.Y.; Morokuma, K.; Voth, G.A.; Salvador, P.; Dannenberg, J.J.; Zakrzewski, V.G.; Dapprich, S.; Daniels, A. D.; Strain, M.C.; Farkas, O.; Malick, D.K.; Rabuck, A.D.; Raghavachari, K.; Foresman, J.B.; Ortiz, J.V.; Cui, Q.; Baboul, A.G.; Clifford, S.; Cioslowski, J.; Stefanov, B.B.; Liu, G.; Liashenko, A.; Piskorz, P.; Komaromi, I.; Martin, R.L.; Fox, D.J.; Keith, T.; Al-Laham, M.A.; Peng, C.Y.; Nanayakkara, A.; Challacombe, M.; Gill, P.M.W.; Johnson, B.; Chen, W.; Wong, M.W.; Gonzalez, C.; Pople, J.A. Gaussian, Inc., Wallingford CT, 2009

[58] C. Lee, W. Yang, R.G. Parr, Development of the Colle-Salvetti correlation-energy formula into a functional of the electron density. Phys. Rev. B. Condens. Matter. $1988 ; 37: 785-789$

[59] A.D. Becke, A new mixing of Hartree-Fock and local density-functional theories J. Chem. Phys. 1993;98:1372-1377.

[60] W.J. Hehre, R. Ditchfield, J.A. Pople, Self-consistent molecular orbital methods. XII. Further extensions of Gaussian-type basis sets for use in molecular orbital studies of organic molecules. J. Chem. Phys. 1972;56:2257-2261.

[61] J. Tomasi, B. Mennucci, E. Cances, The IEF version of the PCM solvation method: an overview of a new method addressed to study molecular solutes at the QM ab initio level. J. Mol. Struct. THEOCHEM 1999;464:211-226. 
[62] G. Scalmani, M.J. Frisch, Continuous surface charge polarizable continuum models of solvation. I. General formalism. J. Chem. Phys. 2010;132:114110.

[63] N.M. O'Boyle, A.L. Tenderholt, K.M. Langner, cclib: A library for packageindependent computational chemistry algorithms. J. Comp. Chem. 2008;29:839-845. https://doi.org/10.1002/jcc.20823

[64] Kurdyukova, I.V.; Ishchenko, A.A.; Derevyanko, N. A.; Mysyk, D.D. synthesis and spectral properties of merocyanine dyes derived from tetra-nitrofluorene and heterocycles of various electron-donating ability, Chem. Heterocycl. Comp. 2013;49, 281-293.

[65] Kamlet, M.J.; Abboud, J.-L.M.; Abraham, M.H.; Taft, R.W. Linear solvation energy relationships. 23. A comprehensive collection of the solvatochromic parameters, .pi.*, .alpha., and .beta., and some methods for simplifying the generalized solvatochromic equation, J. Org. Chem. 1983;48:2877-2887.

[66] Reichardt, C. Solvatochromic Dyes as Solvent Polarity Indicators. Chem. Rev. 1994;94:2319-2358.

[67] Lippert, E.Z. Dipolmoment und Elektronenstruktur von angeregten Molekülen. Naturforsch. 1955;10a:541-545 http://zfn.mpdl.mpg.de/data/Reihe_A/10/ZNA-195510a-0541.pdf

[68] Catalan, J. On the ET (30), $\pi^{*}$, Py, S‘, and SPP empirical scales as descriptors of nonspecific solvent effects J. Org. Chem. 1997;62:8231-8234

[69] Catalan, J.; Lopez, V.; Perez, P.; Matin-Villamil, R.; Rodriguez, J. G. Progress towards a generalized solvent polarity scale: The solvatochromism of 2-(dimethylamino)-7nitrofluorene and its homomorph 2-fluoro-7-nitrofluorene, Liebigs Ann. 1995 ;2:241252.

[70] Kawski, A. Zur lösungsmittelabhängigkeit der wellenzahl von elektronenbanden lumineszierender moleküle und über die bestimmung der elektrischen dipolmomente im anregungszustand. Acta Phys. Polon. 1966;29:507-518.

[71] Mcrae, e.g. theory of solvent effects on molecular electronic spectra. frequency shifts, J. Phys. Chem. 1957;61:562-572. 
[72] Suppan, P. Solvent effects on the energy of electronic transitions: experimental observations and applications to structural problems of excited molecules, J. Chem. Soc. A 1968:3125-3133.

[73] Bakshiev, N.G. Universal intermolecular interactions and their effect on the position of the electronic spectra of molecules in two component solutions, Opt. Spektrosk. 1964;16:821-832.

[74] Catalan, J. Toward a generalized treatment of the solvent effect based on four empirical scales: dipolarity (SdP, a new scale), polarizability (SP), acidity (SA), and basicity (SB) of the medium, J. Phys. Chem. B 2009;113:5951-5960.

[75] del Valle, J.C.; García Blanco, F.; Catalán, J. Empirical parameters for solvent acidity, basicity, dipolarity, and polarizability of the ionic liquids [BMIM][BF4] and [BMIM][PF6], J. Phys. Chem. B 2015;119:4683-4692.

[76] Palomar, J.; Torrecilla, J.S.; Lemus, J.; Ferro, V.R.; Rodriguez, F. Prediction of nonideal behavior of polarity/ polarizability scales of solvent mixtures by integration of a novel COSMO-RS molecular descriptor and neural networks, Phys. Chem. Chem. Phys. 2008;10:5967-5975.

[77] Pommerehne, J.; Vestweber, H.; Guss, W.; Mahrt, R. F.; Bässler, H.; Porsch, M.; Daub, J. Efficient Two Layer Leds on a Polymer Blend Basis. Advanced Materials 1995, 7 (6), $551-554$.

[78] Cardona, C. M.; Li, W.; Kaifer, A. E.; Stockdale, D.; Bazan, G. C. Electrochemical Considerations for Determining Absolute Frontier Orbital Energy Levels of Conjugated Polymers for Solar Cell Applications. Adv. Mater. 2011, 23 (20), 2367-2371.

[79] Alam, S.; Shaheer Akhtar, M.; Abdullah, A.; Kim, E.-B.; Shin, H.-S.; Ameen, S. Planar D- $\pi$-A configured dimethoxy vinylbenzene based small organic molecule for solutionprocessed bulk heterojunction organic solar cells, Appl. Sci. 2020, 10, 5743.

[80] Liu, Y.; Sun, Y.; Li, M.; Feng, H.; Ni, W.; Zhang, H.; Wan, Y.; Chen, Y. Efficient carbazole-based small-molecule organic solar cells with an improved fill factor, RSC Adv. 2018, 8, 4867-4871.

[81] Roquet, S.; Cravino, A.; Leriche, P.; Alévêque, O.; Frère, P.; Roncali, J. Triphenylamine-Thienylenevinylene Hybrid Systems with Internal Charge Transfer as 
Donor Materials for Heterojunction Solar Cells, J. Am. Chem. Soc. 2006, 128, 34593466. 